\title{
El Poder en las Relaciones Sexuales: Inicio de un diálogo entre profesionistas en salud reproductiva
}

Population Council

Interagency Gender Working Group (IGWG)

Follow this and additional works at: https://knowledgecommons.popcouncil.org/departments_sbsr-pgy

Part of the Domestic and Intimate Partner Violence Commons, and the Family, Life Course, and Society Commons

How does access to this work benefit you? Let us know!

\section{Recommended Citation}

"El Poder en las Relaciones Sexuales: Inicio de un diálogo entre profesionistas en salud reproductiva." New York: Population Council, 2001. 

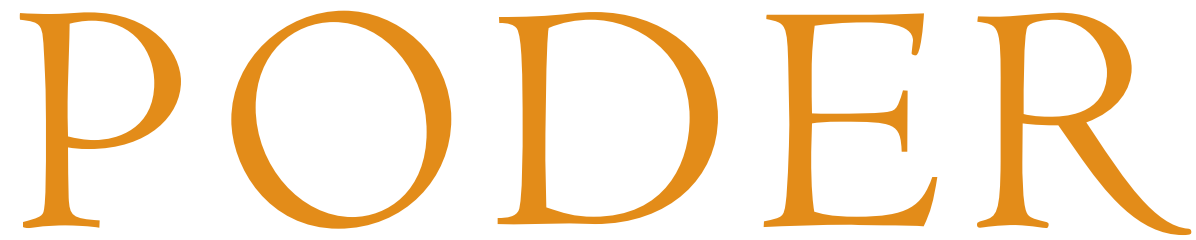 \\ EN LAS RELACIONES SEXUALES}

Inicio de un diálogo entre profesionistas en salud reproductiva

\section{(2) Population Council}

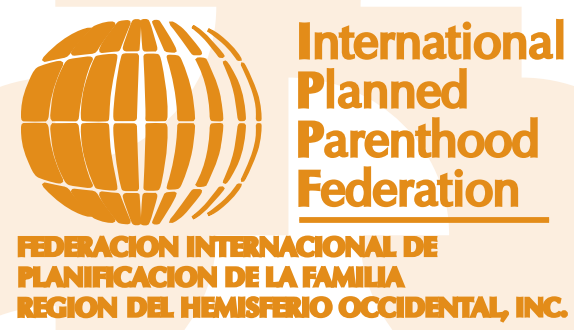




\section{Population Council}

One Dag Hammarskjold Plaza

New York, New York 10017

teléfono: 2 I2-339-0500

fax: 212-755-6052

e-mail: pubinfo@popcouncil.org

www.popcouncil.org

\section{IG WC}

Agencia Estadounidense para el

Desarrollo Internacional (USAID)

1300 Pennsylvania Avenue, NW

G/PHN/POP/PE3.6.142B

Washington, DC 20523

teléfono: 202-712-0662

fax: 202-216-3046

e-mail: IGWG@usaid.gov
Federación Internacional de

Planificación de la Familia,

Región del Hemisferio Occidental

I20 Wall St., 9th Fl.

New York, NY 10005

teléfono: 2I2-248-6400

fax: 2I2-248-422I

email:info@ippfwhr.org

web: www.ippfwhr.org

El Population Council (Consejo de Población) es una institución internacional no gubernamental sin fines de lucro que busca el mejoramiento del bienestar y de la salud reproductiva de las generaciones actuales y futuras en el mundo; igualmente procura ayudar a lograr un balance humano, sostenible y equitativo entre la gente y los recursos existentes. El Population Council conduce investigaciones en ciencias sociales, biomédicas y en salud pública, y fomenta la investigación en países en desarrollo. Establecido en 1952, el Consejo es gobernado por una junta directiva de miembros internacionales. Sus oficinas centrales están en Nueva York y desde ahí sostienen una red global de oficinas regionales y nacionales.

Fundado en 1997, el Grupo de Trabajo Interagencial sobre Género (Interagency Gender Working Group o IGWG) es una red de organizaciones no gubernamentales, que incluye a las agencias cooperativas de la Agencia Estadounidense para el Desarrollo Internacional (USAID), y al Centro para la Población, la Salud y la Nutrición (PHN) de la USAID. La IGWG promueve la equidad de género dentro de los programas del PHN, para poder lograr mejores resultados en cuanto a la salud reproductiva y el VIH/SIDA, y coadyuvar al logro de un desarrollo sostenible.

Copyright (C) 200 I por The Population Council, Inc.

Cualquier parte de esta publicación puede ser fotocopiada sin el permiso de los autores o el editor, siempre y cuando se den los créditos correspondientes a la publicación original, y que dichas copias se distribuyan de manera gratuita. Cualquier reproducción comercial requiere del permiso previo y por escrito del Population Council.

Está publicación fue originalmente producida en inglés por el Population Council. La traducción y publicación de la versión en español fue realizada por la Federación Internacional de Planificación de la Familia, Región del Hemisferio Occidental (IPPF/RHO) con apoyo parcial de la Fundación Ford.

Para copias adicionales, favor contactar a la IPPF/RHO. Para obtener copias adicionales en español, favor contactar a la IPPF/RHO. Una versión electrónica también está disponible en la dirección: http://www.popcouncil.org/pdfs/poder.pdf. Para obtener copias en inglés, una versión electrónica está disponible en la dirección http://www.popcouncil.org/pdfs/ power.pdf, o contacte al Population Council.

El financiamiento de este documento fue aportado por la USAID. Las ideas expresadas por los autores no necesariamente reflejan los puntos de vista o las políticas de la USAID. 


\section{ÍNDICE}

Prólogo

Reconocimientos vii

Introducción viii

El Poder en las Relaciones Sexuales: ¿Qué Evidencias Existen? 1

Esfuerzos Desarrollados en el Campo: la Entrega de Servicios 14

Esfuerzos Desarrollados en el Campo: la Comunidad 19

Esfuerzos Desarrollados en el Campo: la Socialización 26

Comentarios de la Comunidad de Patrocinadores

y de las Agencias Implementadoras $\quad 31$

Una Mirada al Futuro: los Grupos de Trabajo 43

$\begin{array}{lr}\text { Comentarios Finales } & 48\end{array}$

Apéndice: los Participantes $\quad 51$ 



\section{PRÓLOGO}

Durante la mayor parte de su historia, el campo de la salud pública y población ha evitado la cuestión de la sexualidad y el reconocimiento de que las diferencias de poder en las relaciones sexuales entre hombres y mujeres cumplen un papel importante. Antes de la epidemia del VIH/SIDA se justificó este silencio por medio de la creencia de que dichas relaciones eran "privadas", que los actos entre la pareja eran plenamente voluntarios, que las personas se mostrarían reacias a discutir su comportamiento y salud sexuales $y$, finalmente, que aun cuando se considerase deseable la intervención, por razones de salud pública u otras, sería demasiado difícil lograr cambios en las relaciones sexuales.

La Conferencia Internacional sobre Población y Desarrollo de El Cairo de I994, así como la Conferencia sobre Mujeres de Beijing de 1995, públicamente pusieron punto final a este silencio, al enfocarse en la forma en que el género influye la toma de decisiones en materia de salud reproductiva así como de relaciones sexuales. Los participantes de la Conferencia de Beijing adoptaron una resolución que condena la coerción sexual. Esta resolución fue promovida por mujeres de culturas modernas y tradicionales, y sirvió como una declaración abierta de que, para muchas mujeres, gran parte de la actividad sexual no era segura ni voluntaria y — se atrevió a declarar- tampoco placentera.

Mujeres y defensores de la salud de la mujer no han sido los únicos en preocuparse sobre la comunicación, la igualdad y el poder en las relaciones sexuales. Profesionistas en salud pública y desarrollo social, así como muchos hombres, empezaron a expresar su preocupación acerca de cómo los roles de género masculino también estaban limitando la vida de los hombres — llevándolos hacia relaciones sexuales desiguales y riesgosas para ellos- y fomentando muchos resultados negativos para la sociedad, como altos índices de infecciones transmitidas sexualmente y de violencia sexual.

A pesar de que en años recientes se haya reconocido el papel del poder en las relaciones sexuales, a esta concepción le ha faltado en gran medida una expresión práctica en el campo de la salud reproductiva. Las discusiones resumidas en este informe indican que las desigualdades de poder, basadas en el género, entorpecen la comunicación entre parejas, limitan la habilidad de individuos y parejas para hablar de sus metas en cuanto al espaciamiento de los hijos y al tamaño de la familia, o de lograrlas. Asimismo, limitan el uso efectivo de los servicios de salud reproductiva, socavan el logro de salud y placer sexuales de hombres y mujeres, e incrementan significativamente su vulnerabilidad ante el VIH/SIDA y otras infecciones de transmisión sexual.

Los esfuerzos internacionales para reducir el impacto del SIDA ponen de manifiesto cada vez más la desigualdad de poder en las relaciones sexuales como un factor vital en la creciente epidemia, especialmente entre adolescentes y adultos jóvenes. En algunas partes del mundo, en donde la epidemia está en pleno apogeo, la proporción entre las tasas de infección femenina y masculina de personas entre las edades de $15 \mathrm{y}$ 24 años, es de 8 a 1. Como señaló Paul Delay en el transcurso de esta reunión, el VIH se ha convertido "esencialmente en una epidemia de mujeres jóvenes impulsada por la conducta masculina”.

Este informe resume los trabajos realizados durante una reunión organizada en respuesta a un creciente interés en el tema, y copatrocinada por el Population Council y el Subcomité sobre Hombres y Salud Reproductiva del Grupo de Trabajo Interagencial sobre Género de la USAID. Muchas de las organizaciones asistentes 
creyeron que era ya imperativo iniciar un diálogo sobre el poder en las relaciones sexuales, y sobre la sexualidad misma, para reafirmar lo que ya sabemos, y para instar urgentemente a un proceso de aprendizaje continuo, alimentado por la investigación diagnóstica y por programas experimentales cuidadosamente observados.

La participación en esta reunión fue diseñada para que fuese ecléctica: los profesionistas en salud reproductiva, preocupados por este tema, durante mucho tiempo han sentido que necesitan la asesoría y la perspectiva de aquéllos que tienen un conocimiento más profundo de la sexualidad per se, ya que su propia perspectiva está limitada por puntos de vista demasiado convencionales. Incluso se buscó el consejo de aquéllos que tienen una perspectiva sociológica acerca de cómo los muchachos y muchachas, hombres y mujeres construyen su identidad sexual. Finalmente, no podremos avanzar mucho en este debate sin mejorar los instrumentos de medición —algunos provenientes de campos lejanos - para poder definir y observar dimensiones significativas del poder en las relaciones sexuales y poder documentar la habilidad de las intervenciones para cambiarlas.

Esta reunión fue un llamado a la acción. Entre los 141 participantes había la percepción unánime de que la desigualdad en las relaciones sexuales es una cuestión vital para la salud pública y el desarrollo social. Los participantes señalaron la necesidad de realizar un mayor esfuerzo en áreas múltiples: trabajo teórico continuo, análisis descriptivo sociológico y psicológico, investigaciones operacionales, por nombrar sólo algunos. La evidencia presentada indica que es posible lograr dichos cambios de conducta y actitud. Escuchamos acerca del progreso logrado en ocho intervenciones basadas en trabajo de campo, todas de las cuales suministraron información valiosa y un solo mensaje abrumador: muchos hombres $y$ mujeres, en países menos desarrollados, ya están listos para discutir la cuestión de la desigualdad en las relaciones sexuales y creen que hay que hacer cambios. Escuchamos miembros de agencias patrocinadoras e implementadoras decir que ya han tomado nota de estos asuntos y que la sexualidad y el poder en las relaciones sexuales se han convertido en el tema central en algunos de sus programas. Y significativamente, escuchamos a aquéllos que dirigen la lucha en contra del VIH/SIDA. Dentro de esta comunidad, cambiar la dinámica entre hombres y mujeres y dentro de las relaciones sexuales y “dotar de poder" al miembro más débil de la pareja (generalmente, pero no siempre, una mujer) se han convertido en puntos vitales de la intervención.

De esta manera esperamos que este informe inspire a los miembros de la comunidad de la salud reproductiva a comprometerse $y$ a responder a este llamado mediante la acción.

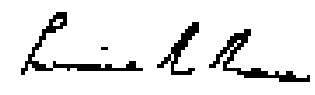

Purnima Mane, Population Council

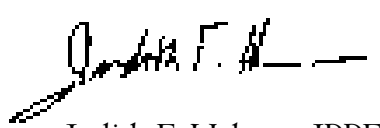

Judith F. Helzner, IPPF/RHO y el Subcomité sobre Hombres y Salud Reproductiva de la USAID

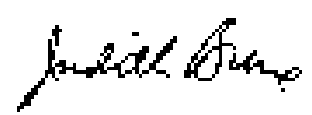

Judith Bruce, Population Council

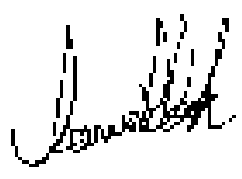

Sam Clark, PATH

y el Subcomité sobre Hombres

y Salud Reproductiva 


\section{RECONOCIMIENTOS}

La reunión sobre el poder en las relaciones sexuales que se realizó en Washington, D.C. los días I y 2 de marzo de 200I fue un esfuerzo conjunto de las oficinas de Nueva York y de Washington, D.C. del Population Council y del Subcomité sobre Hombres y Salud Reproductiva del Grupo de Trabajo Interagencial sobre Género de la USAID. Agradecemos al Subcomité por el patrocinio financiero y el apoyo que brindaron a la realización y publicación de este informe. Agradecemos también a la Agencia Sueca de Cooperación para el Desarrollo Internacional (SIDA por sus siglas en inglés) por su liderazgo en esta agenda y su financiamiento para la reunión.

Agradecemos a Ann Leonard por insistir en este tema y darle alta prioridad en la agenda del Population Council. Ella y Judith Helzner, del Subcomité, lideraron esta reunión como representantes de sus respectivas organizaciones. Otros colegas del consejo trabajaron incesantemente en la conceptualización y planificación de esta reunión, incluidas Sandra Bjegovic, Judith Bruce, Erica Chong, Rachel Goldberg, Michelle Gray, Purnima Mane, Carey Meyers, Julie Pulerwitz, Naomi Rutenberg, y Ellen Weiss. Gracias también a Sarah
Douglass, Emily Knox, Eva Roca, y Melissa VanderKooi de la oficina del Council en Washington, D.C., por suministrar apoyo logístico durante la reunión. PATH amablemente nos ayudó a conseguir el lugar para la reunión.

También le agradecemos a Ann Blanc por asumir el reto de preparar la revisión actualizada de la literatura sobre el poder en las relaciones sexuales. Esta revisión sirvió como punto de partida para nuestras discusiones durante la reunión. Contamos con un grupo de ilustres y dedicados ponentes — demasiado largo para nombrarlo, pero que está incluido en el reporte- que nos guió durante los dos estimulantes días que duró la reunión.

Rachel Goldberg conceptualizó el reporte, escribió cada resumen y supervisó su producción. Sin embargo, este producto final representa la colaboración del trabajo de muchos: Michal Avni, Susan Bloodworth, Sam Clark, Margaret Greene, Rebeca Quiroga, y Karin Ringheim fungieron como anotadores. Debbie Rogow ofreció sugerencias valiosísimas de redacción, comentarios de revisión, y contribuciones para el texto. $Y$ Sandra Bjegovic brindó ayuda técnica durante el proceso de redacción. 


\section{INTRODUCCIÓN}

\section{por Dra. Carmen Barroso, Directora Regional, IPPF/RHO}

Yo atendí esta reunión sobre el Poder en las Relaciones Sexuales en el 200I como Directora de Población y Salud Reproductiva de la Fundación MacArthur, porque los vínculos entre el poder y el sexo han informado la creación de subvenciones en la MacArthur desde el principio. En el 2003, como la nueva Directora de la Federación Internacional de Planificación de la Familia, Región del Hemisferio Occidental, siento un compromiso renovado para avanzar los derechos, la equidad de género y la justicia social a través de una red de entrega de servicios de 45 Asociaciones Miembro por toda Latinoamérica y el Caribe. Estamos comprometidos al avance de los derechos y la salud sexual y reproductiva para lograr derechos humanos universales y la justicia social, regional y globalmente.
IPPF/RHO cree que los derechos y la salud sexual y reproductiva deben ser componentes esenciales de estrategias para el alivio de la pobreza y la eliminación de inequidades sociales. A la vez, los problemas de la salud sexual y reproductiva sólo se pueden resolver enfrentando sus causas bases —las inequidades de género, la discriminación social y la pobreza-y enfrentando las inequidades de género junto a otras inequidades. Esto significa traspasar el área de participación masculina, que muchas veces implica la acusación masculina, para ofrecer soluciones para equilibrar las relaciones de género y potenciar a todo individuo, no sólo ciertos grupos de individuos. Abrir un diálogo sobre estas dos fuertes palabras -PODER y SEXO_ - entre profesionales en salud reproductiva de diferentes sectores e instituciones, ha sido un paso en la dirección correcta, pero nos queda a nosotros continuar por este camino. 


\section{EL PODER EN LAS RELACIONES SEXUALES: ¿QUÉ EVIDENCIAS EXISTEN?}

\section{Observaciones de inicio}

\section{(Margaret Neuse)}

La sesión de apertura fue presidida por Margaret Neuse, Directora de la Oficina de Población de USAID. Neuse hizo una reflexión acerca de la confianza histórica en ciertos métodos anticonceptivos en contraste con otros dentro del campo de la planificación familiar y de la población. Los métodos que han sido favorecidos no sólo ofrecen la más eficaz protección contra el embarazo, sino también requieren poca o ninguna intervención de los miembros de las parejas para su uso o en la toma de decisiones. Como resultado, pocos programas tienen experiencia en la discusión del uso de métodos en el contexto de las relaciones sexuales.

Neuse notó el creciente reconocimiento en el campo de la planificación familiar de que la toma de decisiones sobre cuestiones sexuales, incluso el uso de anticonceptivos, es algo complejo y frecuentemente involucra muchos otros actores además de la mujer (o el hombre en el caso de la vasectomía). Ha habido algunos esfuerzos exitosos en cuanto a la participación masculina, pero estos son relativamente a pequeña escala y con frecuencia no son bien evaluados. Ella propuso destinar suficientes recursos para el aprendizaje, la cuantificación, y la valoración de las cuestiones de poder en las relaciones sexuales, y cómo este poder se relaciona con el uso de anticonceptivos y de decisiones en este respecto.
Ella subrayó que la diseminación del $\mathrm{VIH} / \mathrm{SIDA}$ exige una gran aceleración en el aprendizaje y el proceso de aplicación. El uso del condón, el único medio que efectivamente bloquea la transmisión del $\mathrm{VIH}$, requiere de la comunicación y la solución de algunas de las relaciones de poder y dinámicas sexuales. Aquéllos que laboran en dicho campo tienen ahora una doble responsabilidad — la de mantenerse enfocados primordialmente en la planificación familiar y la salud reproductiva, $y$ la de definir y asumir su propio papel en la lucha contra esta epidemia. Neuse concluyó declarando que para ambos fines es indispensable tener una comprensión del poder en las relaciones sexuales.

\section{Los efectos del poder en las rela-} ciones sexuales y la salud sexual y reproductiva: un examen de la evidencia (Ann Blanc) ${ }^{\mathrm{I}}$

La primera sesión se centró en la revisión del estado de las investigaciones en el área del poder y las relaciones sexuales, para la cual el Population Council comisionó a Ann Blanc ${ }^{\mathrm{I}}$ a preparar para esta reunión. Blanc trató los siguientes puntos:

I. Revisar lo que se ha aprendido hasta la fecha acerca del papel que juega el poder de género en las relaciones sexuales en la determinación de las consecuencias en la salud reproductiva y sexual;

\footnotetext{
${ }_{1}$ Ann Blanc trabajaba anteriormente con el programa de Encuestas Demográficas y de Salud (Demographics and Health Surveys, o EDS) y actualmente es presidente de su propia compañía de consultoría de demografía.
} 
2. Derivar lecciones de las intervenciones clínicas y basadas en la comunidad que se enfocan en el poder; $y$

3. Remarcar los vacíos en el conocimiento y las áreas de prioridad para futuras intervenciones e investigación

Blanc le dijo al grupo que se quedó sorprendida por la magnitud de lo que ya es conocido. Ella revisó principalmente la literatura sobre la planificación familiar enfocada en uniones heterosexuales; sin embargo, también incluyó perspectivas derivadas del trabajo en otros aspectos de la salud reproductiva, incluyendo el VIH/SIDA. A continuación se presentan algunas de las observaciones más significativas.

\section{Pensar acerca del poder}

Blanc señaló una distinción entre "poder para" (la habilidad para actuar) y "poder sobre" (la habilidad para afirmar deseos y metas aun frente a la oposición de otra persona). Ella argumentó que lo importante al examinar el papel del poder en las relaciones sexuales, no es el poder absoluto de alguno de los miembros de una pareja, sino la influencia comparativa de cada uno de los miembros. Ella agregó que las desigualdades de género operan dentro del contexto de otros tipos de desequilibrio de poder —aquéllos basados en la raza, riqueza, o la edad-e interactúan con ellos.

\section{¿Cuáles son las consecuencias de la desigualdad en el poder?}

Las características a nivel individual, de pareja, de familia, y de la comunidad influyen tanto el equilibrio del poder como la medida en que los individuos tienen acceso a los servicios de salud reproductiva. Las relaciones de poder basadas en el género pueden tener un efecto directo en la habilidad de las parejas para obtener información, para tomar decisiones, y para realizar acciones relacionadas a su salud reproductiva, su seguridad, y su bienestar.

\section{La toma de decisiones reproductivas}

La relación entre la toma de decisiones sobre la reproducción y el poder basado en género es compleja. Con frecuencia, una mujer y su pareja pueden no estar de acuerdo en desear un embarazo o en el uso de anticonceptivos. Sin embargo, y a pesar de muchas investigaciones, la evidencia sobre quién tiene la opinión de mayor peso a la hora de tomar una decisión de carácter reproductivo no puede ser generalizada a través de diferentes contextos, y aun dentro del mismo contexto, la evidencia no siempre ha sido consistente.

Los estudios han mostrado que aunque la mayoría de los hombres dice aprobar la planificación familiar en el abstracto, el uso de anticonceptivos en sus propias parejas con frecuencia crea preocupaciones y resistencia. Las preocupaciones expresadas por los hombres incluyen el miedo de que ellos pierdan su papel como jefes de familia, que sus parejas se vuelvan promiscuas o adúlteras, y que ellos sean puestos en ridículo por otros miembros de la comunidad. Aunque los hombres son generalmente los que toman las decisiones en materia de planificación familiar, pueden dejar la implementación de sus decisiones a sus parejas. Esta actitud es reforzada por aquellos servicios que tienden a dedicarse exclusivamente a la mujer. 
Aquellas mujeres que perciben que sus maridos no las apoyarán en su decisión de usar anticonceptivos pueden llegar a utilizar algún método subrepticiamente. El uso abierto de la anticoncepción, en oposición a los deseos de la pareja, ya sean reales o percibidos, significa una cuestión difícil para muchas mujeres, especialmente aquéllas que son económicamente dependientes de su pareja y aquéllas cuya pareja puede amenazarlas con la separación, el divorcio o la violencia. Sin embargo, el uso subrepticio tiene su precio también: el ir contra la voluntad de un marido es visto como impropio de una buena esposa, el miedo de ser descubierta es una carga constante, y el buscar la ayuda médica para problemas o efectos secundarios es complicado.

\section{El uso de los servicios de salud reproductiva} Las diferencias en el poder influyen directamente el acceso de las mujeres a los servicios de salud reproductiva y su uso. Una de las maneras más concretas en que esto ocurre es a través del control de los hombres de los recursos financieros y de la movilidad de sus esposas. Esto no significa necesariamente que los hombres nieguen el cuidado de salud a las mujeres adrede. Sin embargo, la ignorancia acerca de la salud reproductiva de las mujeres puede conducirlos a conceptos erróneos y a una toma desinformada de decisiones.

\section{La salud sexual y el placer en los bombres}

Las relaciones desiguales de poder pueden tener una influencia dañina también en la salud sexual de los hombres. La información limitada disponible sobre este tema sugiere que tanto los problemas físicos como los psicosexuales son comunes entre los hombres. Sin embargo, la preocupación de los hombres de ser vistos como fuertes y en control puede desanimarlos a discutir sus problemas de salud sexual con sus parejas o con otros, incluyendo a los prestadores de servicios médicos.

\section{La violencia basada en género}

La violencia basada en género tiene una multitud de efectos negativos sobre la salud sexual y reproductiva de las mujeres. Además de la agresión inmediata, el daño del bienestar físico y mental de las mujeres puede incluir depresión, ansiedad, problemas ginecológicos y complicaciones del embarazo (incluyendo pérdida del feto). La violencia sexual puede resultar en un embarazo no deseado e infecciones transmitidas sexualmente (ITS). Incluso, el miedo del abuso puede inhibir el deseo de las mujeres de rehusarse a tener relaciones sexuales no deseadas o de tocar el tema de los anticonceptivos o el uso del condón, dejando a muchas mujeres y muchachas en riesgo de un embarazo no deseado y de la adquisición de ITS.

\section{Vulnerabilidad bacia el VIH/SIDA e infecciones transmitidas sexualmente}

Estudios cuantitativos han demostrado que el incremento en el poder entre las mujeres está frecuentemente asociado con un incremento en el uso del condón. Sin embargo, dado que se espera que las mujeres sean ignorantes y pasivas acerca de las cuestiones sexuales, es difícil para ellas informarse acerca de las estrategias de reducción de riesgos. Aun entre mujeres y muchachas informadas, la 
desigualdad en el poder reduce sus habilidades para negociar la protección contra enfermedades, para expresar sus preocupaciones acerca de la fidelidad sexual y para rehusarse a tener relaciones sexuales. $\mathrm{Su}$ dependencia económica en los hombres aumenta aún más su vulnerabilidad: esto incrementa la probabilidad de que se sometan a prácticas sexuales riesgosas para asegurar contra el abandono o a cambio de dinero o favores. En culturas donde la virginidad es altamente valorada, las mujeres pueden ser presionadas por hombres mayores a tener relaciones sexuales, o pueden recurrir a prácticas tales como el sexo anal como forma de conservar su virginidad, aunque esto las coloca en mayor riesgo de contraer ITS.

Creencias acerca de la masculinidad y su asociación con el poder, la autosuficiencia y el correr riesgos contribuyen también a la vulnerabilidad de los hombres hacia el VIH/SIDA. Las relaciones sexuales múltiples les son permitidas a los hombres, o por lo menos no condenadas en muchas sociedades. Esto conduce algunos hombres a buscar muchas parejas, incluso dentro del comercio sexual, a pesar de estar conscientes de los riesgos. Además, la expectativa de los hombres de ser autosuficientes los desanima a buscar información acerca del sexo o de protegerse contra las enfermedades, y los hace negar la existencia de los riesgos.

\section{¿Qué han demostrado las inter- venciones que se han enfocado en el poder?}

Además de lo que hemos aprendido de las investigaciones enfocadas en las cuestiones de pareja (es decir, que la inclusión masculina con frecuencia promueve la salud reproductiva y que tanto mujeres como hombres buscan un papel más activo para el miembro masculino de la pareja), hay un número de lecciones derivadas de las intervenciones que consideran directamente cuestiones de género y poder.

\section{El bombre que quiere participar enfrenta barreras}

Aunque mujeres y hombres generalmente dan la bienvenida a una mayor participación del miembro masculino de la pareja en cuestiones de salud reproductiva, los hombres que desean participar en lo relativo a la salud de mujeres o niños pueden enfrentar barreras que surgen de la normas sociales acerca de los papeles apropiados de cada género. Otros hombres y parientes pueden reaccionar negativamente, y los sistemas de servicios también pueden hacerlos sentirse incómodos. Las instalaciones pueden no contar con espacio para que esperen a su pareja, y los trabajadores de la salud les pueden negar el acceso a las salas de parto o de obstetricia. En algunos estudios, los hombres han reportado que han sido tratados groseramente, o les han hecho sentir que no tienen una razón válida para estar ahí.

\section{Los clientes desean discutir cuestiones sexuales}

Hay evidencia significativa de que los clientes usualmente se sienten aliviados y contentos de que los prestadores de servicios se preocupen y les pregunten acerca de su vidas sexuales. Sin embargo, el que hombres y mujeres estén dispuestos a hablar acerca de cuestiones sexuales no 
significa que lo encuentren necesariamente fácil. De hecho, la capacitación intensiva de los prestadores (sobre temas como sexualidad, género, y poder), y el apoyo continuo posterior a la capacitación parecen ser esenciales para que ellos puedan dirigirse eficazmente a los clientes.

\section{Modelos de intervención}

Blanc categorizó los enfoques de intervención que han reconocido las relaciones de poder o que han intentado influir en ellas en un rango que se extiende desde la más básica hasta la más ambiciosa:

- Proporcionar información a los clientes que reconozca explícitamente el rol de las parejas en las alternativas de salud reproductiva y en los resultados;

- Mejorar el intercambio de información entre clientes y proveedores y discutir el contexto de las relaciones sexuales;

- Promover la educación y la comunicación de la pareja;

- Proveer información a la pareja de la clienta e invitarle a participar en los servicios;

- Integrar la dinámica de las relaciones sexuales dentro de los servicios para hombres; $y$

- Buscar el cambio en las normas y prácticas de la comunidad.

\section{Retos programáticos}

Aquéllos que han intentado desarrollar programas que influyan el poder en las relaciones sexuales frecuentemente se han enfrentado a la crítica de que el género y las relaciones son un componente de la "cultura", visto como impermeable o inapropiado de ser objeto de una intervención externa. No obstante, algunos programas que han abordado de una manera sensible las prácticas y creencias tradicionales incorporadas en la gente han tenido éxito.

Un dilema para los programas es cómo respetar el deseo de mujeres u hombres que quieren usar la planificación familiar a pesar de la oposición de su pareja. Los prestadores necesitan reconocer que existirán legítimos desacuerdos dentro de las parejas, y evaluar las necesidades de los individuos frente a las necesidades de la pareja. Se debe tomar en consideración los derechos y las responsabilidades de cada miembro de la pareja.

En muchos medios, miembros femeninos de la familia proporcionan ayuda, información, y cuidado a las mujeres embarazadas y/o recién paridas. Es importante que no haya ningún debilitamiento de los apoyos tradicionales positivos. En algunos grupos, el extenso interés de la familia por los hijos puede ser un fuerte incentivo para continuar procreando, aun si la pareja prefiere limitar el tamaño de su familia. Los programas que buscan influir el poder en las relaciones dentro de las parejas necesitan reconocer la amplia gama de actores que participan en la toma de decisiones relacionadas con la salud reproductiva y sexual.

La incomodidad del personal de clínicas y otros programas en la discusión de temas sensibles como el sexo y la violencia sexual es inevitable. Los programas que han incorporado capacitación en dichos tópicos han encontrado alguna resistencia inicial por parte del personal, vergüenza, y algunos prejuicios personales que pueden inhibir la consulta. No obstante, muchos programas también 
han encontrado que la incomodidad inicial del personal puede ser superada, aunque esto puede tomar algún tiempo y requerir del apoyo continuo a dichos prestadores de servicios.

\section{Retos metodológicos}

Una de las deficiencias de la investigación hasta la fecha es el pequeño número de modelos cuantitativos rigurosos que especifiquen el lazo entre el poder en las relaciones sexuales y la salud sexual y reproductiva. El poder en sí mismo rara vez es cuantificado; por ello, si ocurre un resultado deseado con frecuencia no es posible atribuirlo a un cambio en el poder en las relaciones. Son muy necesarios los estudios que relacionen una intervención con cambios en el poder, y de ahí con un resultado específico en la salud.

Tales investigaciones sin duda han sido inhibidas por la falta de una definición de poder aceptada comúnmente y por la ausencia de formas de medición útiles y prácticas en las relaciones de poder. Se han considerado un número de enfoques metodológicos para la medición del poder, incluyendo medidas (o formas de registro) de la relativa participación de parejas en la toma de decisiones, de los lugares de control, de la autonomía de las mujeres, y de la toma de poder por parte de las mujeres. No está claro todavía si estas medidas pueden ser utilizadas fuera del medio en donde se emplearon y diseñaron.

\section{Retos éticos mayores}

Tal como se mencionó anteriormente, los programas de planificación familiar inevitablemente se enfrentan a la cuestión de las parejas que están en desacuerdo en cuanto al uso o no de la anticoncepción o de otros métodos en particular, así como al deseo de las mujeres de usar la anticoncepción aun en secreto. En el área del diagnóstico y tratamiento de ITS, los programas de notificación a parejas deben considerar aspectos de confidencialidad y de protección a los clientes. De manera similar, la detección de la violencia basada en género y la proporción de un apoyo adecuado a aquéllas que reporten violencia requiere evaluar el daño potencial contra el beneficio que puede ser alcanzado.

\section{Prioridades para el futuro}

Desarrollar intervenciones que directamente enfoquen el balance de poder en las relaciones sexuales

Los aspectos más importantes (y difíciles) son la elaboración, implementación, y evaluación de intervenciones que directa e intencionalmente se enfoquen en el equilibrio del poder dentro de las relaciones sexuales. Tales intervenciones deben incluir - aunque esto represente dificultades en la etapa de desarrollo y validación - líneas de base y seguimiento de las relaciones de poder.

\section{Diversificar, escalar y documentar las intervenciones que enfocan el poder}

Es imprescindible una mayor documentación de una gama de entornos con una variedad de tipos de intervención. Conforme se acumulan los estudios, se podrá generar una base de evidencia que describe lo que es factible y lo que es 
aceptable bajo diferentes circunstancias. También hace falta trabajar más sobre la evidencia acerca de la adaptación y el mejoramiento de las intervenciones que parezcan prometedoras.

\section{Abordar cuestiones de pareja a nivel indivi- dual y de la pareja}

Hay una gran necesidad de evaluar la efectividad relativa al suministro de servicios para parejas en contraste con servicios para individuos, y existe un área muy extensa de estudio sobre la secuencia de estos servicios (quizá habría que empezar con los individuos y después pasar a tratarlos en tanto a la pareja). Algo indispensable en el trabajo inmediato es encontrar una forma programática de usar las interacciones de los servicios de salud con el fin de que la pareja mejore su comunicación. Finalmente, debemos probar diferentes tipos de estrategias de comunicación para encontrar la más eficaz en neutralizar los desequilibrios en el poder basado en el género.

\section{Intervenir y conducir investigaciones en múltiples niveles}

A pesar de reconocer que el poder en las relaciones sexuales es el resultado de procesos que operan en múltiples niveles, es inusual que los programas introduzcan intervenciones en dichos niveles. Aún más apremiante es la necesidad de investigaciones que examinen el poder de género y su impacto en múltiples niveles (individual, familiar y comunal, por ejemplo).

\section{Identificar un enfoque sobre el poder que} sea específico para relaciones sexuales entre adolescentes
Los y las adolescentes están construyendo su identidad sexual, haciéndose independientes de sus padres, y son particularmente susceptibles a la presión de grupo; por ello, son un público clave para intervenciones que intentan enfocarse en el poder en las relaciones sexuales. Sin embargo, como han notado numerosos observadores, dichas intervenciones deben estar basadas no en la experiencia y perspectivas que se deriven de nuestras observaciones de adultos, sino sobre las distintas realidades de las parejas sexuales adolescentes. Incluso entre muchachas adolescentes hay por lo menos dos subgrupos - muchachas solteras que pueden ser ocasionalmente activas sexualmente $y$ que generalmente desean evitar un embarazo, y muchachas casadas que están con parejas sexuales regulares y con frecuencia están intentando tener hijos o están bajo presión para hacerlo. La socialización de muchachos y muchachas continúa creando dinámicas de poder en las relaciones sexuales que ponen en desventaja a las mujeres jóvenes y que no son benéficas para los hombres jóvenes.

\section{Conclusión}

Un mayor progreso en el área del poder dentro de las relaciones sexuales requiere tanto de una disposición para estar abiertos a la experimentación y a enfoques creativos como de un esfuerzo para simultáneamente avanzar en la investigación y en el diseño de programas. La investigación ha demostrado que la eficacia en la medición de la dinámica entre el género y el poder yace dentro del terreno del diseño práctico del estudio de campo. A pesar del escepticismo inicial en muchos 
lugares, los programas han mostrado que los desequilibrios en el poder basados en el género no son necesariamente impermeables a la intervención. Una gama de actores en los programas, que incluye mujeres y hombres, prestadores de servicios de salud y la población en general, ha demostrado flexibilidad y adaptación al cambio. Mientras que aún quedan muchos retos, la evidencia hasta la fecha sugiere una retribución considerable al trabajo que se ha hecho al reconocer que el papel del poder de género debe constituir un rasgo integral de los programas de salud sexual y reproductiva.

Este documento puede encontrarse por entero y con referencias completas en la edición de septiembre del 2001 de Studies in Family Planning.

Los estudios y las investigaciones sobre la planificación familiar ofrecen una perspectiva demasiado convencional y limitada sobre el poder en las relaciones sexuales (Participante \#1, Richard Parker) Richard Parker, de Columbia University, la Universidad Estatal de Río de Janeiro, y la Asociación Interdisciplinaria Brasileña sobre SIDA, enfocó sus comentarios en la última de las tareas señaladas en el documento de Blanc llamando atención hacia algunos de las lagunas y los problemas que necesitarán ser mencionados en el futuro. Lo que generalmente encontró más impactante al ver el resumen de las investigaciones fue lo notoriamente convencional que ha sido el trabajo sobre el poder en las relaciones sexuales dentro del campo de la planificación familiar. Señaló cinco áreas en las que se ve expresada este convencionalismo:
La definición misma del poder como es usada en el campo de la planificación familiar es demasiado estrecha

La literatura sobre planificación familiar presta poca atención a una serie de desarrollos sobre la reflexión e investigación del poder desde una perspectiva más amplia. Parker dijo que hasta que nosotros empecemos a incorporar dentro de las ciencias de la salud algunas de las revelaciones teóricas con relación al poder, desarrolladas en las ciencias sociales, teme que estemos destinados a repetir mucho del trabajo que ya ha sido realizado. Es importante enfatizar que el poder es un producto social que es socialmente construido, producido, y reproducido. El punto más importante de esta comprensión es el que llama nuestra atención a la cultura, una palabra que tampoco aparece en estos estudios de ninguna manera significativa.

\section{La literatura sobre programas aborda la práctica reproductiva más que la sexualidad} En la mayor parte de la literatura que Blanc revisó, estuvieron ausentes las cuestiones más amplias — las prácticas, los significados, y las representacionesrelacionadas a la sexualidad. Al restringir el enfoque en relaciones heterosexuales, principalmente relaciones heterosexuales reproductivas, perdemos un gran cuerpo de investigación que explora el poder en el género, pero que no se enfoca únicamente en la sexualidad reproductiva. ${ }^{2} \mathrm{El}$ incluir esta investigación dentro de la discusión sería un paso útil hacia una discusión más amplia sobre las maneras en que el poder funciona en la sexualidad. 


\section{El contexto social dentro del cual está} enmarcado el enfoque de los estudios de campo de la planificación familiar es muy limitado

Parker considera sorprendente que aspectos mayores como el cambio social, la globalización, la reestructuración de las relaciones sociales, políticas, y económicas no sean mencionados, como si la sexualidad existiese en un vacío sin ninguna relación con el contexto social más amplio en el que tiene lugar. Esto es particularmente sorprendente en relación con la sexualidad, ya que nosotros hemos observado en recientes décadas la desintegración del patriarcado en diversos países y culturas del mundo, el cambio de formas familiares, y el ascenso de los fundamentalismos. Debemos problematizar la sexualidad más ampliamente si vamos a diseñar investigaciones que no pasen por alto estos fenómenos.

\section{Debemos reconsiderar nuestras estrategias de intervención y metodologías de investigación}

Las intervenciones, según señala el documento de Blanc, se pueden clasificar desde las que proporcionan información hasta las que transforman las normas de la comunidad. Sin embargo, si tratamos al poder como una forma de organización estructural, afirmó Parker, entonces debemos comenzar a pensar en intervenciones estructurales. También puso en tela de juicio la fe que ponemos en la medición y en las pruebas de control al azar; él sugirió que la prueba de control al azar, que fue diseñada como medio para probar la eficacia de diferentes tipos de medicamentos y procedimientos médicos, ha sido hasta cierto punto adaptada acríticamente y aplicada a la investigación sobre el cambio social en maneras que necesitan ser cuestionadas. Finalmente, Parker argumentó que el individuo no debería ser visto como la única unidad de investigación y análisis, sino que también deberían ser consideradas las parejas y las comunidades como unidades de estudio.

\section{Debemos reconocer las dimensiones políticas de las relaciones}

Los derechos sexuales y reproductivos son tan importantes como la salud sexual y reproductiva si queremos entender qué es el poder y cómo funciona en las relaciones sexuales. Lo que nosotros estamos viendo son cuestiones políticas y cambios políticos, y ahí es, fundamentalmente, donde yace una comprensión del poder y una comprensión de cómo cambiar el poder.

Parker finalizó diciendo que si podemos avanzar en relación a estas cuestiones, también podremos avanzar en términos de construir un entendimiento comprensivo del poder y de cómo funciona, $y$ de conceptualizar cómo podríamos cambiar el desequilibrio del poder de manera más efectiva.

\footnotetext{
2 Ejemplos de estos estudios son el de Davis y Kennedy sobre las relaciones lesbianas en Buffalo (Elizabeth Lapovsky Kennedy y Madeline D. Davis. 1993. Boots of Leather, Slippers of Gold: The History of a Lesbian Community [Botas de cuero, pantuflas de oro: la bistoria de una comunidad lesbiana]. New York: Penguin Books); el trabajo de Annick Prieur sobre sexoservidores trangenéros y sus parejas en la Ciudad de México (Annick Prieur. 1998. Mema's House, Mexico City: On Travestites, Queens, and Machos. [La casa de Mema, Ciudad de México: sobre travestis, reinas y machos]. Chicago: University of Chicago Press); y ensayos en la colección de Murray y Roscoe sobre chicos que son esposas y esposos que son mujeres en el África sub-sahariana (Stephen O. Murray and Will Roscoe [Eds.]. 1998. Boy-Wives and Female Husbands: Studies of African Homosexualities. [Chicos que son esposas y esposos que son mujeres: estudios sobre bomosexualidad en África]. New York: St. Martin's Press.).
} 
Los programas de servicio pueden y deben enfocar de manera práctica las diferencias de poder entre hombres $y$ mujeres (Participante \#2, Jeff Spieler)

Jeff Spieler, de la Oficina de Población de la Agencia Estadounidense para el Desarrollo Internacional (USAID), ofreció una discusión práctica del documento de Blanc. Apuntó que el embarazo no deseado, las ITS, y el VIH/SIDA son las mayores amenazas para la salud reproductiva hoy en día, y que el uso infrecuente del condón es la principal barrera para la prevención del VIH. Así, Spieler subrayó la necesidad de enfocarse en los desequilibrios del poder basados en el género dentro de las relaciones sexuales. Las diferencias en el poder entre hombres y mujeres afectan profundamente la habilidad de las mujeres para negociar el uso del condón.

La estigmatización de los condones, debido a su asociación con el sexo ilícito, con la promiscuidad, y con una reducción en la espontaneidad sexual y el placer, es una gran barrera para el uso del condón. Estos estigmas son especialmente dañinos para las mujeres, a quienes frecuentemente les falta el poder para negociar el uso del condón en un acto sexual. A menos que los condones sean desvinculados de implicaciones negativas tales cómo multiples parejas, esta desestigmatización no tendrá lugar. Una forma de lograr esta desvinculación, argumentó Spieler, es el promover el condón como un método eficaz tanto para la prevención del embarazo como la de enfermedades. La evidencia preliminar mostró que aun los grupos de alto riesgo, tales cómo las servidoras sexuales, son más consistentes y competentes en el uso del condón cuando lo utilizan principalmente para prevenir el embarazo más que para prevenir ITS. ${ }^{3}$

Para entender las barreras en el uso del condón, debemos considerar la construcción social de la masculinidad en muchas de las sociedades con las que estamos tratando y en las cuales los problemas son mayores. Spieler remarcó el argumento de Blane de que la identidad masculina está frecuentemente asociada con el poder, la autosuficiencia, y el correr riesgos, lo que contribuye a la propia vulnerabilidad de los hombres a contraer el VIH/SIDA. Por otro lado, se espera que las mujeres sean ignorantes sobre cuestiones sexuales, y por ello frecuentemente carecen de la información adecuada sobre los métodos de prevención. Aun aquellas mujeres que han tenido acceso a la información no son enteramente capaces de negociar la protección, ya sea insistiendo en el uso del condón o rehusándose a las relaciones. Varios estudios conducidos en la República Democrática del Congo (antes Zaire), Uganda, y Ruanda subrayan este desequilibrio, mostrando que el uso del condón es significativamente más alto entre parejas donde la mujer es positiva al VIH, en contraste con aquellas parejas en las que el hombre es el infectado. Esta inhabilidad para negociar está fuertemente ligada a la situación económica inferior de las mujeres: la frecuente

\footnotetext{
${ }^{3}$ Mathias Aklilu et al. 200I. "Factors associated with HIV-I infection among sex workers of Addis Ababa, Ethiopia" "'Factores asociados con la infección HIV-I entre sexoservidoras de Adis Ababa, Etiopía”] AIDS I5(I): 87-96.
} 
dependencia de las mujeres de los hombres hace que ellas tengan miedo al abandono y a la destitución que podría ser resultado de una confrontación o abandono de sus parejas.

Spieler concluyó diciendo que debemos ser innovadores en la promoción de estrategias para el uso del condón, ya que enfrentamos una batalla cuesta arriba para hacer que hombres y mujeres usen un producto que muchos son renuentes o incapaces de usar. La investigación sobre la relación entre el poder y la sexualidad ha sido limitada porque el poder ha sido un concepto difícil de cuantificar y definir. Sin embargo, lo que está claro de los recientes programas es que estos desequilibrios de género, socialmente inculcados, no son imposibles de cambiar, y que los programas tienen que desarrollar estrategias creativas para llegar a los hombres.

\section{El poder en las relaciones sexuales está inextricablemente ligado al equi- librio del poder entre hombres $y$ mujeres y a consideraciones más amplias sobre equidad en el desarro- 1lo (Participante \#3, Geeta Rao Gupta)}

Geeta Rao Gupta, del Centro Internacional para la Investigación sobre las Mujeres, comenzó su presentación comentando que el interés en el equilibrio de poder entre mujeres $y$ hombres ocurre dentro del contexto de un renovado interés en la equidad e igualdad como metas de desarrollo (ver tabla). Este reciente énfasis en el enfoque social para el desarrollo se produce debido al creciente reconocimiento del tremendo costo
La "Desigualdad” En la Salud es la diferencia entre grupos basada en indicadores objetivos. La "falta de equidad" en la salud es un subgrupo de desigualdades juzgadas injustas en tanto que son evitables e injustas. En la Conferencia Mundial sobre Mujeres en Beijing en 1995, los participantes debatieron qué término usar. La ONU, con apoyo de los ONGs, escogió usar el concepto de "igualdad" porque las definiciones de justicia, inherentes en la definición de equidad, eran subjetivas y diferían grandemente entre los participantes de diferentes contextos ideológicos, mientras que la igualdad podría ser definida más objetivamente.

económico, social, y político asociado con las persistentes desigualdades que son injustas e inevitables.

Aplicando lo que se ha aprendido de las investigaciones que Blanc revisó, así como de su propia experiencia programática, Gupta discutió diferentes dimensiones críticas del poder:

\section{Tipos de poder: "Real" vs. "Percibido"}

Gupta definió el "poder real” como los atributos reales que coinciden con la forma en que la sociedad ve y define el poder (ej., educación, dinero, liderazgo). "El poder percibido" es derivado de una fuerte asociación en el agregado entre una característica singular (tal como ser un hombre) y los atributos asociados con el poder. Ella remarcó la importancia de cambiar el poder percibido; sin embargo, dijo que la única manera eficaz y sostenible para un cambio de percepciones es crear cambios en el poder real, porque 
GuPta leyó las palabras de una joven esposa abandonada de la India, quien participó en un programa de su pueblo cómo trabajadora social de la comunidad, como ejemplo de una definición de la toma de poder:

Mi madre y mi abuela me dijeron que no bablara con nadie. Yo no conocía nada más allá de este pueblo cuando llegué por primera vez aquí. No podía visitar a nadie, no tenía permiso de ir a bodas, pero algo mágico sucedió al ser parte de este proyecto. Abora puedo salir del pueblo e ir yo sola a la oficina de correos, a las oficinas del gobierno local y a las del distrito, para bacer lograr distintas cosas. Antes, nadie me enseñó nada, solo me cargaron de restricciones. Yo simplemente vivía por vivir. Abora quiero vivir cómo un ser bumano. Abora no me gustaría vivir así, ni dejaría que nadie más viviera así. La gente decía, “Qué va a bacer ella?" Ahora la misma gente viene a mí para pedirme ayuda. Yo no tuve mucha educación. Abora yo insisto en que mi bermana se eduque, y también las muchachas del pueblo. Ahora las muchachas tienen la oportunidad de aprender, de jugar. Dicen, "Olvidémonos del pasado. Nosotras no somos como nadie más." Yo nunca olvidaré lo que las personas en este programa me ban enseñado. contexto donde dicho acceso no es la norma (en el agregado) no les dará necesariamente mayor poder en las relaciones sexuales. Para que las mujeres puedan obtener dicho poder, las intervenciones individuales deben ser complementadas con esfuerzos para cambiar la imagen del conjunto (agregado) del estatus socio económico de las mujeres.

\section{Contenido del poder: Capital económico, bumano, y social vs. agencia para actuar} Gupta aseguró que el dotar de poder a los individuos requiere de reforzar el acceso a los recursos y de fortalecer la capacidad de acción individual para el uso de esos recursos, la toma de decisiones, y la conducción del liderazgo. Lo primero, dijo ella, es concreto; lo segundo es "mágico" (porque uno puede crear las condiciones idóneas para esto, pero no puede garantizar el resultado). El habilitar la toma de poder dentro de las intervenciones de desarrollo incluye la creación de oportunidades de aprendizaje para la resolución de problemas y para la toma de decisiones, la modificación de las prácticas y percepciones de instituciones y líderes locales, y la construcción de relaciones solidarias dentro de las comunidades y entre individuos e instituciones locales. Un sentido de capacidad de acción o toma de poder, si bien está objetivamente asociado con muchos resultados positivos de salud y desarrollo, es en sí mismo en gran medida subjetivo y es una percepción personal de cómo se siente uno en relación con otros y con su entorno. Por lo tanto, la cuantificación de la toma de poder requiere indicadores subjetivos que puedan capturar esta percepción o experiencia. 


\section{Discusión}

El primer conjunto de discusiones estuvo caracterizado por una tensión, presente durante la reunión, entre la discusión más amplia de qué se necesita para cambiar las fuerzas sociales que crean desequilibrios en el poder y el enfoque más práctico y táctico de la búsqueda por reformar las intervenciones tradicionales (mejorando de manera creciente los modelos existentes de servicios de salud reproductiva). En esta discusión, como en otras, muchos ponentes reconocieron la necesidad de enfocar ambos aspectos, pero había claros prejuicios, como se evidencia en las comentarios que siguen.

Para el cuestionamiento más amplio:

La mayoría de nosotros viene de un contexto de salud pública, así que el escuchar acerca de estos cambios estructurales puede ser un poco abrumador. Hay un número de cosas que podemos hacer dentro de nuestro trabajo para llevar esto a cabo — por ejemplo, integrar la violencia sexual dentro del trabajo de programas ya existentes. Necesitamos reflexionar sobre lo que ya bacemos y sobre cómo podemos ser más sensibles. Yo estoy en el campo de aquéllos interesados en el efecto de $A$ sobre $B$ después de controlar a $C$. Me siento optimista acerca de la posibilidad de medir y evaluar cuantitativamente el impacto sobre los resultados de la salud sexual y reproductiva. Si echamos un vistazo a lo que ba sido becho anteriormente, bay mucho de bueno, incluyendo la medición en niveles múltiples.

Es suficientemente ambiguo que aspectos como la participación masculina generen una diferencia apropiada en términos de salud pública para que sea apropiado apegarnos a las pruebas de control al azar, a pesar de lo que se dijo esta mañana. Un ejemplo concreto de lo que puede suceder cuando procedemos sin prestar atención al análisis y la investigación del género subyacente, puede ser visto en el caso de la promoción del condón. Investigaciones recientes en Brasil basadas en estudios sobre la masculinidadban encontrado que las quejas de bombres $y$ muchachos sobre la reducción del placer sexual con los condones son en gran medida un pretexto socialmente aceptable de una mayor preocupación sobre el desempeño sexual (es decir, el razonable temor de perder una erección mientras se coloca el condón). Aunque bemos gastado decenas de millones de dólares en campañas de promoción del condón, las campañas ban pasado completamente por alto de este fenómeno. 


\section{ESFUERZOS DESARROLLADOS EN EL CAMPO: LA ENTREGA DE SERVICIOS}

La exploración de esfuerzos desarrollados en el campo comenzó con la presentación de dos programas diseñados para producir un cambio en el nivel de entrega de servicios. El primero describía la necesidad de examinar las dinámicas de poder social y del poder en las relaciones sexuales de los propios proveedores como una precondición para habilitarlos para ayudar a sus clientes con sus propios dilemas. El segundo demostró que existe una demanda, tanto como un precedente, para incluir a los hombres en ciertos aspectos de la salud reproductiva, pero que los proveedores y los sistemas de entrega de servicios deben adaptar sus actitudes y prácticas para ajustarse a esta demanda.

$$
\begin{aligned}
& \text { AL DISENAR el programa de } \\
& \text { capacitación para proveedores, el equi- } \\
& \text { po de investigación entendió la difi- } \\
& \text { cultad de traducir la idea del "poder". } \\
& \text { Para el propósito de la intervención } \\
& \text { consideraron que los principales com- } \\
& \text { ponentes de la "toma de poder" eran: } \\
& \text { - Conocimiento } \\
& \text { - Autoconfianza } \\
& \text { - Habilidades de negociación } \\
& \text { - Conciencia } \\
& \text { - Habilidades comunicativas }
\end{aligned}
$$

Dotar de poder a los clientes equivale a dotar de poder a los proveedores: un ejemplo de Pakistán (Anrudh Jain y Zeba Sathar) ${ }^{4}$

Anrudh Jain y Zeba Sathar, del Population Council, describieron un proyecto en Pakistán titulado "Introducción de un enfoque centrado en el cliente para servicios de salud reproductiva”. Los principales objetivos de la intervención eran suscitar un cambio en la actitud y comportamiento de los proveedores, y dotar de poder a los clientes para que se comprometieran de manera más activa en su propia salud reproductiva. La intervención, que tuvo lugar en un distrito rural pobre en Punjab, tomó en cuenta investigaciones previas que conectaban resultados de salud reproductiva con la restringida movilidad de las mujeres pakistaníes, sus recursos limitados, y su falta de poder en el hogar.

La intervención incluía la capacitación de 95 proveedoras comunitarias de salud que trabajaban para el Ministerio de Salud o para el Ministerio de Población y Bienestar Social. Estas mujeres eran nativas de las comunidades a las que servían, y por lo tanto tenían el mismo tipo de represiones o restricciones que las/los clientes a quien ellas servían, incluyendo limitaciones de movilidad y del control

\footnotetext{
${ }^{4}$ Para mayor información sobre este proyecto, contáctese a Zeba Sathar a la dirección zsathar@pcpak.org.
} 
sobre sus ganancias — factores considerados críticos en la capacitación.

Los objetivos del entrenamiento de los proveedores eran:

- Elevar la conciencia sobre poder e igualdad en la vida diaria de las propias proveedoras, en la vida de sus clientes, y en las interacciones con sus clientes; $y$

- Enseñarles habilidades de comunicación que respondieran a estas dinámicas de poder.

Los ejercicios incluían el diagramado de fuentes de poder, la discusión de maneras alternativas para "abrir un puño cerrado" en lugar del poder físico, y el definir tipos y grados de poder. El entrenamiento de las habilidades de comunicación enfatizó la necesidad de ser respetuosas, de identificar las necesidades en la salud reproductiva de las/os clientes más allá del problema inmediato (ej., a través de preguntas abiertas), y de discutir las realidades domésticas de las/los clientes. Específicamente, las proveedoras aprendieron a observar quién tenía el poder en el hogar (por ejemplo, el marido y la suegra); a asegurarse de establecer sus intenciones en cuanto a la salud reproductiva, así como las del o la cliente al negociar soluciones apropiadas; y a cerciorarse de que al final de una visita el o la cliente hubiera entendido y fuera capaz de implementar el curso de acción acordado.

A partir de las entrevistas en grupos de discusión, las respuestas de los capacitadores, estudios de proceso, y las visitas de las ponentes (los resultados del estudio del análisis situacional todavía
LOS CAMBIOS EN LA ACTITUD Y CONDUCTA se

hicieron evidentes al escuchar las palabras de las mujeres:

Anteriormente bablábamos frente a todos, abora evaluamos quiénes tienen el poder de tomar decisiones en el bogar y primero bablamos con ellos. . . luego con la cliente. . nosotras tratamos de ayudar a aquellas mujeres que no pueden bablar con sus maridos, a través de un sentimiento de autoconciencia y de mostrarles que sí pueden.

Mis clientes pensaban que yo era muy joven, me sentía intimidada, no podía bablar abiertamente, pero abora (después de la capacitación) bablo con confianza y ellos se abren y me cuentan todo.

no están disponibles), es evidente que la capacitación ha tenido una influencia significativa en la vida de las proveedoras, tanto privada cómo profesional. Ellas reportan mayor confianza para moverse fuera de sus casas, y mayor seguridad expresándose en sus propias relaciones maritales, y tomando acción contra la violencia doméstica y el acoso en el trabajo. Ellas también reportan el tener más paciencia con sus propios hijos. Los cambios en su conducta profesional incluyen esfuerzos deliberados para estar en pie de "igualdad" con sus clientes (ej., sentarse al mismo nivel cuando están en sus casas, evitar la enseñanza unilateral, y pasar más tiempo con sus clientes). Ahora ellas consideran y se enfocan en otras fuentes de poder, por ejemplo, lidiar con la influencia del marido a través de la suegra. Finalmente, ellas generalmente se sienten más motivadas y emocionadas con su trabajo. 
Integrar a los miembros masculinos

de las parejas dentro de la ecuación

de la salud reproductiva: Un ejemplo

\section{de Kenya (Esther Muia) ${ }^{5}$}

Esther Muia, de la oficina en Nairobi del Population Council, presentó un estudio para examinar la aceptabilidad y factibilidad de integrar a los miembros masculinos de las parejas dentro de los servicios de salud reproductiva en Kenya. A pesar de la influencia de los hombres en la capacidad de las mujeres para acceder a los servicios e implementar regímenes de cuidado, las investigaciones documentaron que los miembros masculinos de las parejas estaban realmente marginados dentro de la corriente principal de los servicios de salud reproductiva. Muia y sus colegas buscaban entender el papel real y potencial de los hombres como parejas de apoyo al identificar su participación actual; evaluar las actitudes de las mujeres, sus parejas, y los proveedores de servicio hacia la participación de los hombres; e identificar las barreras para una mayor participación de las parejas masculinas.

Llevaron a cabo su estudio en 1998 en un hospital provincial de un área mayoritariamente rural de la Provincia Occidental de Kenya y en un hospital urbano de Nairobi. Se usaron técnicas cualitativas y cuantitativas para recolectar información de las mujeres que recibían servicios (hospitalizados o externos) de salud reproductiva, de los hombres que acompañaban a sus parejas, de los miembros de parejas que no acompañaban a las mujeres que se atendían (a los que se les hizo un seguimiento en el trabajo, en casa, o en otra parte de la comunidad), y de los proveedores de servicio. Un tercio de las mujeres en el lugar urbano estaban acompañadas de sus parejas, en comparación con un sexto en la población rural.

La gran mayoría de los entrevistados de ambos sexos indicó que la participación de los hombres fue deseada en las visitas prenatales, de posparto, y de planificación familiar. Una abrumadora proporción (94\%) de las mujeres dijo que le gustaría que sus parejas estuvieran presentes durante sus consultas para asegurarse de que entendían y apoyaban los consejos del doctor. Una proporción aún mayor (98\%) de hombres dijeron que les gustaría estar presentes. A pesar de la falta de un precedente cultural así cómo de una fuerte oposición de los proveedores (ver abajo), el 50\% de las mujeres y el $46 \%$ de los hombres dijeron que sería apropiado que el hombre estuviera presente en la habitación donde sus mujeres dieran a luz. Las opiniones de los proveedores de servicio eran en su mayor parte similares a las de sus clientes: pensaban que las parejas deberían estar presentes durante la consulta y al discutir la condición del cliente; una proporción mucho menor (1\%-5\%) quería que los hombres estuvieran presentes al examinar a las pacientes o en la habitación donde dieran a luz.

Muia identificó que los factores clave que obstaculizaban la participación masculina eran:

\footnotetext{
${ }^{5}$ Para una discusión más profunda de este estudio, véase Esther Muia et al. 2000. "Integrating men into the reproductive health equation: Acceptability and feasibility in Kenia," ["Integrar a los miembros masculinos de las parejas dentro de la ecuación de la salud reproductiva: adaptación y factibilidad en Kenia”.] New York: Population Council; o contáctese a Esther Muia a la dirección emuia@popconcuil.or.ke.
} 
Las áreas donde les gustaría a los entrevistados ver una mayor participación del miembro masculino de la pareja en los servicios de salud reproductiva

\begin{tabular}{lcrr} 
Service type & $\begin{array}{r}\text { Respuestas } \\
\text { de mujeres } \\
(\mathrm{N}=697)\end{array}$ & $\begin{array}{r}\text { Respuestas } \\
\text { de hombres } \\
(\mathrm{N}=284)\end{array}$ & $\begin{array}{r}\text { Respuestas } \\
\text { de los proveedores } \\
\text { de servicios (N=196) }\end{array}$ \\
\hline Cuidado Prenatal & $632(91 \%)$ & $253(89 \%)$ & $118(60 \%)$ \\
Consulta & $655(94 \%)$ & $279(98 \%)$ & $98(50 \%)$ \\
Examen & $468(67 \%)$ & $183(64 \%)$ & $2(1 \%)$ \\
En sala de parto & $438(63 \%)$ & $176(62 \%)$ & $10(5 \%)$ \\
Durante el parto & $351(50 \%)$ & $132(46 \%)$ & $10(5 \%)$ \\
Visitas Postparto & $644(92 \%)$ & $257(90 \%)$ & $88(45 \%)$ \\
FP clínica & $622(89 \%)$ & $246(87 \%)$ & $98(50 \%)$ \\
Pago de servicios & $669(96 \%)$ & $182(64 \%)$ & $176(90 \%)$
\end{tabular}

- Financieros (costo de transporte para dos personas, tiempo libre del trabajo, parejas que laboraban lejos de casa);

- Presión social, cultural y de grupo (ciertas actividades no son consideradas "varoniles");

- Institucionales (hacinamiento, falta de privacidad, actitudes de los proveedores); $y$

- Mala comunicación (entre la pareja, y entre clientes y proveedores).

Hay muchos puntos importantes que se pueden desprender de este estudio: que hombres, mujeres, y proveedores consideran que hay un mayor espacio para la participación masculina en los servicios reproductivos prestados a sus parejas; que los hombres están participando actualmente a pesar de los obstáculos; que la participación masculina es vista como más apropiada y aceptable en ciertos servicios de salud reproductiva; y que mujeres, hombres y proveedores de servicios no siempre están de acuerdo sobre cuando debe de incluirse a los hombres. Tomando en cuenta estas lecciones, ha sido propuesta una intervención para el oeste de Kenia que funcionará con clientes femeninos, sus parejas y proveedores en varios niveles de provisión de servicios para obtener maneras apropiadas y aceptables de incrementar la participación de los hombres en ciertos servicios de salud reproductiva. Esto podría incluir crear las actividades de crear un espacio para los miembros acompañantes de las parejas; incluir a los hombres en ciertos aspectos de la provisión de servicios tales como asesorías y consultas; determinar maneras apropiadas y medios para compartir información sobre las necesidades de la salud reproductiva de la mujer y de los problemas con sus parejas masculinas; $y$ desarrollar protocolos verbales para abrir la discusión sobre el poder en las relaciones sexuales. 
Discusión

La discusión se centró alrededor de la idea de la presencia masculina en los servicios de salud reproductiva. Un participante notó que los hombres también son frecuentemente excluidos de la salud y el cuidado de niños pequeños. Citó un estudio en Zambia en que los hombres sugirieron que hubiera días especiales en que los padres pudieran llevar a sus niños menores de cinco años a revisiones médicas. Los hombres esperaban llevar a sus hijos a las clínicas para tener acceso a parte de la información que usualmente era dirigida a las madres dentro de los programas de salud materna e infantil.

Otros participantes retomaron una cuestión ética planteada por Blanc: ¿Existe el peligro de que una mayor información y participación masculina perpetúe el control masculino sobre las decisiones femeninas? Dentro del contexto de la asesoría, por ejemplo, existe el peligro de que los proveedores puedan comenzar a hablar a los hombres en vez de dirigirse a la mujer o a ambos miembros de la pareja. 


\section{ESFUERZOS DESARROLLADOS EN EL CAMPO: LA COMUNIDAD}

El segundo grupo de trabajadores de campo describió intervenciones de mayor escala a nivel de la comunidad. El primer ponente describió una intervención de múltiples niveles diseñada para incrementar el diálogo a nivel de la comunidad y para trabajar directamente sobre las normas sociales que gobiernan el poder en las relaciones. El segundo describió un esfuerzo práctico basado en la comunidad y en la clínica que enfoca los roles de los hombres y de las parejas, sus estrategias de comunicación así como la dinámica del poder. Y el tercero explicó cómo de un problema de salud reproductiva de las mujeres surgió el deseo de éstas de trabajar con sus parejas, y los pasos prácticos tomados para incluir a los hombres de la comunidad.

\section{Relacionando salud, desarrollo, y empoderamiento: Un ejemplo de India (Hemant Apte) ${ }^{6}$}

Hemant Apte del Centro de Investigación del Hospital de KEM, habló acerca de la vinculación de la salud con el desarrollo y el empoderamiento en las intervenciones efectuadas en el rural Estado de Maharashta, India. Actualmente las actividades comunitarias del KEM basadas en la comunidad llegan a I50 pueblos con una población total de 200,000.

En un estudio en 1995 de 500 muchachos y muchachas entre los 14 y 22 años

\section{EN LA INDIA, HAY UN DICHO que dice que}

"la identidad de un intelectual no esta completa sin una institución, la de una planta trepadora sin un árbol, ni la de una mujer sin un hombre”. Nosotros queremos que las mujeres reconozcan su humanidad independiente.

\section{- Hemant Apte}

(casados y solteros), el KEM encontró que los adolescentes tenían muy poco conocimiento científico acerca de la salud sexual y reproductiva y que las muchachas tenían menos conocimiento que los muchachos. Se encontró que las cuestiones de salud sexual y reproductiva no sólo eran motivo de preocupación para la pareja, sino para todo el círculo familiar. El estudio confirmó que el equilibrio del poder estaba fuertemente inclinado contra los adolescentes, y particularmente contra las muchachas. Por ejemplo, la mayoría de las adolescentes casadas dijeron que les era imposible rechazar las relaciones sexuales; casi todos los primeros nacimientos tuvieron lugar dentro del primer año de matrimonio porque el dar a luz era visto como el único modo para que una chica se estableciera en el hogar de su marido. Sin embargo, el estudio también encontró que cuando los hombres tenían un cierto grado de independencia económica de sus familias, alguna educación, y habían establecido sus propias familias independientes,

\footnotetext{
${ }^{6}$ Para mayor información sobre este trabajo, contáctese a Hermant Apte en la dirección ham@pn2.vsln.net.in
} 
había una mejor comunicación entre esposos y un papel mayor para las mujeres en la toma de decisiones de salud reproductiva.

El KEM ha establecido una gama de intervenciones, antes del estudio y en respuesta al mismo, para enfocar tanto el empoderamiento de las mujeres como la participación masculina en la salud reproductiva. Entre estas intervenciones existen grupos que promueven la acción colectiva de las muchachas (grupos separados para casadas y solteras), esquemas de generación de ingresos de las mujeres, programas de educación de parejas, y actividades de educación sobre salud reproductiva para hombres.

Apte describió en detalle tres intervenciones mayores:

\section{Discutir la situación de los adolescentes} varones y su papel en la salud reproductiva. Hombres adultos (supervisores de trabajadoras sociales de la comunidad) dirigieron grupos educativos con aproximadamente 20 hombres casados y solteros de edades entre los 16 y los 25 años. Estas sesiones de dos horas cubrieron materias como anatomía y fisiología reproductiva de hombres y mujeres, estereotipos masculinos y femeninos, el rol de los maridos y las parejas, las ITS y el VIH/SIDA. Apte notó que ésta fue la primera vez que estos muchachos habían estado involucrados en una discusión acerca de la anatomía masculina o femenina. A través de una teatralización de los roles, los muchachos comenzaron a reconocer la tremenda desigualdad que impregna las relaciones con sus novias y esposas (ej., al decir "Dame agua, me tengo que lavar la cara" o “'Ya está listo el té?”). Apte dijo que los hombres jóvenes no habían sido conscientes de que ellos estaban ejerciendo tanto poder y control, ni de las consecuencias para sus parejas. Dieciséis de estos jóvenes se han ofrecido voluntariamente para dar esta misma capacitación en sus comunidades.

\section{Programa de educación de parejas.}

Este programa que dura todo un día y trabaja con grupos de 10 a 12 parejas (principalmente jóvenes), cubre la salud reproductiva de mujeres y hombres, la desigualdad entre los géneros que se encuentra por todos lados y la manera inconsciente en que los hombres usan el poder. El principal propósito es fomentar el diálogo sobre estos temas. Para este fin, una de las actividades usadas fue el actuar el papel de los esposos para lo cual un hombre tomó el papel de esposa y otro el rol de marido. Se le pedía a la "pareja" que actuara la rutina de las interacciones en el hogar frente a todo el grupo. Luego al hombre que representó a la esposa se le preguntó cómo se sentía al escuchar lo que iba diciendo su "marido". A través de las diferentes sesiones, los hombres que actuaban cómo esposas admitieron sentirse lastimados y encontraron humillantes las acciones y comentarios de los otros hombres.

\section{Servicios clínicos rurales para mujeres}

Una doctora del Centro de Investigación del Hospital de KEM ofrece servicios clínicos una vez por semana en un hospital rural de 30 camas en Vadu. La doctora habla con las mujeres acerca de sus problemas y también acerca del papel de sus 
maridos; en algunos casos (como cuando se les ha detectado una ITS) se les pide a las mujeres que traigan a sus maridos con ellas en la siguiente visita. Algunos maridos han comenzado a venir con sus esposas. Además de los servicios de salud reproductiva, una psicóloga clínica ofrecerá asesoría sobre cuestiones sexuales cada quince días, con lo cual clientes masculinos y femeninos, podrán venir a la consulta ya sea individualmente o en pareja. El KEM se dio cuenta que, aunque cubría 150 pueblos —una hazaña nada pequeña - aún no estaba cerca de cubrir las necesidades de todo el estado. Por lo tanto, ahora está suministrando capacitaciones para entrenadores de otras partes del estado de Maharashta, sobre varios aspectos de salud reproductiva, incluyendo la participación masculina porque todos estos aspectos se están incluyendo dentro del programa del gobierno.

Fomento de un diálogo de la comunidad sobre sexualidad y salud reproductiva: Un ejemplo de Belice (Jewel Quallo-Rosberg) ${ }^{7}$

Jewel Quallo-Rosberg de la Asociación de Vida Familiar de Belice (BFLA, por sus siglas en inglés), una afiliada caribeña de la Federación Internacional de Planificación de la Familia, describió el cambio de trayectoria de la Asociación de ser un programa centrado clínicas y en monólogos didácticos unidireccionales acerca de métodos anticonceptivos, a un diálogo franco y bi-direccional sobre sexualidad y salud reproductiva conducido en grupos clínicos y comunitarios. Ella describió un proceso en que la comunidad pronta y urgentemente identificó los desequilibrios en el poder que colocaban a las mujeres en situación de vulnerabilidad como víctimas de relaciones sexuales no deseadas, de violencia doméstica, infidelidad, embarazos no deseados, e infecciones transmitidas sexualmente.

El desarrollo de una estrategia apropiada para lidiar con la intensa lucha por el poder entre hombres y mujeres en la esfera íntima, requirió de una gran reflexión para propiciar un proceso que fuera seguro y eficaz para todas las partes. Los hombres en la comunidad se sentían incomprendidos y despojados del poder por la sociedad (muchos de los hombres eran desempleados o tenían un bajo ingreso) así como por sus parejas, y las mujeres sintieron que ellas estaban cargando con una responsabilidad desproporcionada en la familia y que los hombres querían controlar todo y decirles qué hacer. Las mujeres se sentían forzadas a usar métodos anticonceptivos ocultamente (mediante estrategias tales cómo poner píldoras anticonceptivas orales en frascos de vitaminas o mediante inyecciones) ya que si lo hacían al descubierto enfrentarían el abuso verbal y físico.

Entre las estrategias que la BFLA ha intentado están:

- Alterar los protocolos clínicos y capacitar a consejeros para animar a los proveedores a que hagan preguntas acerca de la comunicación y el poder

\footnotetext{
${ }^{7}$ Para mayor información sobre el trabajo de BFLA, contáctese a Jewel Quallo-Rosberg a la dirección bfla@btl.net.
} 


\section{Comunicación entre parejas: Ejercicio de pecera (30-45 minutos con grupos de género mixto).}

PROPÓSITO: Practicar el uso de una buena comunicación de pareja y analizar los problemas que surgen entre los miembros de parejas sexuales.

PREPARACIÓn: Preparar cuatro o más situaciones para que las personas actúen un rol. En cada situación, debe haber un tema o problema para discutir. Aquí hay algunos ejemplos:

- Una mujer cuya pareja está amenazando con abandonarla. Ella quiere que él use condón cuando tienen relaciones.

- Una mujer cuya pareja ha tenido hijos con otras mujeres. Ella depende económicamente de él para el sostén de su familia.

- Una muchacha con un novio mayor que ella. Él quiere que tengan relaciones sexuales ella no está segura de querer hacerlo. Ella lo ama realmente.

- Un hombre quiere que su pareja use planificación familiar. Ella no esta segura de querer hacerlo.

QUE HACER: Solicitar voluntarios para actuar el papel del hombre y la mujer, para que practiquen la comunicación entre ellos mediante la escenificacón de estas situaciones. El resto del grupo observa y ayuda para analizar qué funciona y qué podría ser mejorado. Podría ser útil anotar aspectos que reflejen la definición del grupo de lo que constituye una buena comunicación (ej., una comunicación bi-direccional, escuchar, empatizar) y lo que constituye una mala comunicación. Si es posible, todos deberían tener la oportunidad de actuar un papel y de observar.

Sugerencia para el FAcilitador: Antes de hacer sus comentarios, déle a los que actuaron un papel la oportunidad de manifestar sus ideas respecto a lo que funcionó bien y a lo que les gustaría que hubieran podido hacer mejor. De esa manera los comentarios de los observadores serán más útiles y se percibirán mucho menos como críticas. en las relaciones íntimas, así como reforzar los derechos sexuales y reproductivos de los clientes —usualmente mujeres;

- Al nivel de la comunidad, capacitar a voluntarios para ser facilitadores de grupos regulares de diálogo en donde el género y el poder sean discutidos abiertamente; ${ }^{8}$

- Un programa de educación a padres y madres que los equipe con las habilidades necesarias para comunicarse más efectivamente con sus hijos/as y los libere de papeles de género limitantes y destructivos.

- Establecer sesiones de compañero a compañero para adolescentes —de muchacha-a-muchacha, y de muchacho-a-muchacho- que cubran cuestiones de sexualidad. La BFLA también condujo sesiones domiciliarias en las cuales los padres escuchaban a los adolescentes hablar sobre cuestiones de auto-estima, sexualidad, y de sus sentimientos; $y$

- Presentar obras callejeras escritas por miembros de la comunidad para generar discusión.

El atender a los hombres como grupo separado y especial fue una parte integral de la estrategia de BFLA para incrementar la comunicación entre los sexos y reducir las tensiones. Dichas sesiones eran necesarias para lidiar con el sentimiento, según lo planteó Quallo-Rosberg, de que "los hombres estaban experimentando dolor y ansiedad, pero eran incapaces de expresarlo”. Los grupos formados 
exclusivamente por hombres fueron particularmente valiosos para hacer surgir temas tales como las preocupaciones acerca del desempleo y de la falta de poder masculinos, sentimientos de falta de respeto femenino, cuestiones de control y dominación, así como la disfunción eréctil. También se condujeron grupos de discusión mixtos (masculino/femenino) utilizando un moderador para permitir que hombres $y$ mujeres escucharan las preocupaciones de unos y otros (ver la tabla para ejemplo de un ejercicio usado). Finalmente se creó un ambiente que alentaba a las mujeres a traer a sus parejas y que las hacía sentirse cómodas una vez ahí.

La BFLA está refinando actualmente sus protocolos de servicio para que todos los proveedores de clientes intercambien e incluyan discusiones sobre el equilibrio del poder en las relaciones sexuales. La meta del nuevo protocolo es alentar a que los clientes presentes hablen acerca de la dominación y abuso en la pareja, explorar maneras de negociar con parejas inseguras, así como ayudar a que las relaciones sean de mayor equidad. La agencia también urgirá al personal clínico para que salgan a la comunidad y ayuden en la creación de grupos de apoyo para mujeres en Belice —esto, con el fin de saber si el experimento conducido hasta la fecha en la Ciudad de Belice (en donde la mayoría de los residentes son de origen criollo) será igualmente aceptado en el norte, oeste, y sur del país (donde una gran parte de los residentes son mestizos y garifonas).

\section{La Incorporación de los hombres, desde la perspectiva de las mujeres:} Un ejemplo de Perú (Susana Galdós) ${ }^{9}$ Susana Galdós, del proyecto ReproSalud del Movimiento Manuela Ramos, discutió cómo este proyecto histórico hizo que el cambio del balance del poder en las relaciones sexuales se convirtiera en un elemento central de su trabajo. ReproSalud, un proyecto de gran alcance apoyado por la USAID, va a las comunidades adonde los programas de gobierno y de planificación familiar han fallado enormemente en cuanto a atraer al público. Este programa invierte en el desarrollo social y económico de las mujeres para que sean más capaces de ejercer control sobre sus propias vidas. Aunque la educación en salud reproductiva y la conciencia de género son el enfoque del trabajo de ReproSalud, no menos del 16\% del presupuesto del proyecto fue asignado para esquemas de generación de

\footnotetext{
${ }^{8}$ Para una descripción más detallada de estos grupos de diálogo, véase Lucella Campbell y Mervin Lambey. Por aparecer. "How a family planning association turned its approach to sexual health on his head: Collaborating with communities in Belize" "Cómo una asociación sobre paternidad familiar volteó de cabeza su enfoque de la salud social: colaborando con las comunidades de Belize”.] en Nicole Haberland y Diana Measham (eds.), Responding to Cairo: Case Study of Changed Practices in Reproductive Health and Family Planning (working title). [Cómo responder al Cairo: estudios de caso de prácticas cambiadas en la salud reproductiva y en la planeación familiar.] (Título provisional). New York: Population Council.

${ }^{9}$ Para una discusión más profunda del Movimiento de Mauela Ramos y ReproSalud [Proyecto de Salud Reproductiva en el Perú], véase Debbie Rogow y Judith Bruce. 2000. "Alone you are nobody, together we float: The Manuela Ramos Movement," ["Sola no eres nadie, juntas podemos flotar: el movimiento de Manuela Ramos.”] Quality, Calidad, Qualité. No. I0, New York: Population Council.
} 
GALDÓS PRESENTÓ muestras de los testimonios de los hombres que participaron en los talleres así como los de sus esposas:

Nos ban enseñado sobre la planificación familiar, las enfermedades y cómo cuidar nuestros órganos sexuales. $Y$ nosotros bemos aprendido cómo vivir juntos en familia, que nosotros debemos trabajar por la igualdad y que debemos cuidar de nuestras esposas. Por ejemplo, para vivir sin pelear, para llevar a las mujeres a los centros de salud si se enferman. . . Mi parte favorita del curso se trató de vivir juntos, cuidar de los bijos y de nuestras esposas.

—Lorenzo, promotor

Antes, yo tomaba mucho y golpeaba a mi esposa. Luego me sentía mal y me preguntaba por qué lo bacía. Abora bebo menos y ya no le pego. Hablo con mi bija mayor (nueve años de edad) y la animo a que estudie

—Victorio, edad 30, promotor, Canchabamba. Abora yo puedo bablar con él más abiertamente. Por ejemplo, yo me sentía avergonzada si él me tocaba mucho. Abora puedo decirle donde se siente bien: en la vagina, en el clítoris. Él me pregunta y yo puedo decirle.

$$
\text { —Victoria, edad 32, } 5 \text { hijos, Acopalca }
$$

Antes, cuando nuestros maridos nos golpeaban, nosotras nos sentábamos quietas y llorábamos. Abora no tenemos miedo. Podemos presentar una denuncia; algunas mujeres ya están baciéndolo. Antes no. Simplemente cocinábamos y llorábamos. Antes mi marido era muy difícil. Él fue al entrenamiento y abora es más cariñoso.

—Rosa Maria, edad 35, 7 hijos, Huarimayo

ingreso y para programas de crédito. Galdós explicó cómo un proyecto diseñado únicamente para mujeres funcionó con hombres también.
Uno de los aspectos más innovadores de ReproSalud es el proceso que ha usado para determinar las necesidades de las comunidades a las que sirve. El personal de ReproSalud va a las comunidades y les pregunta a las mujeres qué quieren ellas y qué necesitan, a través de un proceso abierto de auto-evaluación conocido cómo autodiagnóstico. Los problemas comunes de salud reproductiva, identificados por las mujeres, incluyen infecciones del tracto reproductivo, demasiados hijos, problemas durante el embarazo o parto, y violencia. Los ejercicios grupales también habilitan a las mujeres para analizar las raíces sociales de sus problemas de salud. Las mujeres son luego invitadas a organizar un proyecto comunitario para enfocar un problema clave. En estos proyectos ReproSalud entrena a las mujeres en la localidad para educar a otras mujeres de la comunidad y le proporciona al grupo el apoyo técnico y económico necesario.

Según explicó Galdós, conforme las mujeres se involucraron y se emocionaron más al tratar sus problemas desde la raíz, declararon enfáticamente: "necesitamos trabajar con nuestros hombres". Al mismo tiempo, sus maridos querían saber más acerca de los talleres de sus esposas. Inicialmente, el personal había estado preocupado por redirigir los recursos normalmente destinados a las actividades de las mujeres, pero modificó el diseño del proyecto en respuesta a las demandas de las mujeres.

Un grupo de hombres que conocían las culturas e idiomas locales fue seleccionado para asistir a un taller nacional de capacitación para entrenadores. Luego 
estos hombres capacitaron a promotores de los pueblos, quienes siguiendo el modelo de ReproSalud, ofrecieron el taller a otros hombres en sus comunidades. Con una duración de 12 horas, para lo cual el material se dividía en cuatro sesiones, los talleres usaron ejercicios y una intensa discusión para explorar la participación de los hombres en la violencia, el alcoholismo, la sexualidad, y la paternidad; y para discutir la anatomía y la fisiología reproductivas y sexuales, los derechos de las mujeres, roles de género, los métodos anticonceptivos, las cuestiones particulares de salud reproductiva priorizadas por las mujeres en sus comunidades durante los talleres de autodiagnóstico, y el papel de los hombres en la violencia doméstica.

Pruebas anteriores y posteriores al taller demostraron cambios significativos en el conocimiento y actitud de los participantes. Los hombres valoraron la oportunidad de aprender acerca de sus cuerpos y de su sexualidad, y estaban también ansiosos por explorar diferentes maneras para promover la armonía en la familia. Otros beneficios incluían un mayor entendimiento acerca del cuidado personal y de higiene, los derechos de sus esposas (ej., para rehusarse a tener relaciones sexuales), y su propio papel en el cuidado de los hijos. Las desventajas citadas por los hombres participantes en el programa ReproSalud incluían el ser criticados por otros hombres por ser "manipulados", el sentirse amenazados por la mayor capaci- dad de acción y decisión de sus mujeres, y en consecuencia el que ellas fueran menos tolerantes con ellos.

Como parte de una evaluación de varios lugares que se hizo en I999, Debbie Rogow y Alejandro Díaz condujeron la evaluación de un estudio de caso de ReproSalud en varias aldeas de los Andes ${ }^{10}$. Encontraron que los cambios documentados después del entrenamiento habían persistido tras el paso del tiempo. Algunos de los cambios más impresionantes incluían un incremento en la autoestima femenina y masculina, una reducción drástica en el consumo del alcohol y de la violencia doméstica asociada, un marcado incremento en el uso de los anticonceptivos. Muchos de los entrevistados reportaron una mayor toma de decisiones por parte de las mujeres y una mayor distribución de responsabilidades en asuntos familiares.

Finalmente, el entrenar a hombres para trabajar como educadores en sus propias comunidades se ha convertido en una de las facetas más sobresalientes del trabajo de ReproSalud con las mujeres del Perú.

\footnotetext{
${ }^{10}$ Debbie Rogow y Alejandro Diaz. I999. "ReproSalud: Evaluation of project impact in the Chavin region: A case study", ["ReproSalud: Evaluación del impacto del proyecto en la región de Chavin: un estudio de caso"], informe de viaje para USAID/Lima y ReproSalud no publicado.
} 


\section{ESFUERZOS DESARROLLADOS EN EL CAMPO: LA SOCIALIZACIÓN}

El estudio de la socialización es indispensable para entender cómo se crean los papeles de género. Existen razones para creer que los patrones de interacción en las relaciones íntimas se aprenden en la niñez y se "ensayan" durante la adolescencia. Los exponentes compartieron sus enfoques y experiencias así como las conclusiones de varios proyectos en Latinoamérica que intentan enfocar y entender la socialización del género masculino. El primer programa descrito aquí presenta una descripción realista de cambio - mientras los papeles de género y las normas sexuales se van secularizando, algunas normas tradicionales (no necesariamente positivas) van desapareciendo lentamente. El segundo programa descrito enfatiza la heterogeneidad de la población masculina de jóvenes, y explora la situación de jóvenes "equitativos en las relaciones de género". El tercer programa explora cómo la construcción tradicional de la "masculinidad" acarrea riesgos para ambos géneros.

La noche se hizo para los hombres: Cortejo y sexualidad en un pueblo rural en México (Benno de Keijzer) ${ }^{\mathrm{II}}$ Benno de Keijzer de la organización Salud y Género, informó primero sobre la investigación etnográfica que él y su colega Gabriela Rodríguez realizaron en Iguanillas, Puebla. El estudio, llevado a cabo entre tres generaciones de hombres y mujeres a lo largo de dos años, examinó cómo están cambiando el cortejo y la sexualidad.

Los investigadores encontraron un proceso de transformación cultural entre los jóvenes en Iguanillas, Puebla. En general, encontraron una tendencia entre las personas más jóvenes hacia una mayor equidad en el género, y evidencias de una apertura hacia la iniciativa sexual femenina y el derecho al placer sexual. Entre los factores clave que citaron para esta transición cultural se incluyen:

- La migración (cerca de la quinta parte de la población local actualmente vive en los Estados Unidos);

- La escuela secundaria local, relativamente nueva, que ha contribuido a crear una nueva cultura de la "juventud" y una adolescencia extendida;

- Las imágenes de amor y sexualidad en los medios populares de comunicación; y

- Una merma en la influencia de la religión.

Rodríguez y de Keijzer, en un artículo sobre la investigación escriben: "Nuestros informantes adolescentes seducen, aman, y lastiman a las mujeres; pero éstas ya no son tan pasivas, y están reaccionando y tomando ideas de la juventud de otras ciudades, de la escuela, de los medios, y de los emigrantes". ${ }^{12}$

Sin embargo, muchas normas tradicionales todavía se respetan, hasta entre la generación más joven. La virginidad

\footnotetext{
II Para más información sobre este estudio, referirse Rodriguez y de Keijzer (2002) "La noche se hizo para los hombres: cortejo y sexualidad en una comunidad cañera del estado de Puebla”, Edamex y Population Council, México.
} 
femenina todavía se valora, y su "pérdida" es un factor precipitante en la formación de parejas. Todavía se espera que los varones demuestren su desempeño sexual a una edad temprana, y prácticamente todos los hombres jóvenes pasan por la iniciación sexual en los burdeles una vez que empiezan a ganar dinero. Esta iniciación ocurre "a cuerno limpio", es decir, sin condones, y los jóvenes se ufanan de ello. Los informantes también tienden a negar que en su comunidad exista el sexo premarital, el aborto, y la homosexualidad, aunque de hecho ocurren. Según de Keijzer, los hombres adultos típicamente poseen una dualidad en cuanto sus criterios de la sexualidad masculina y la femenina, responsabilizando a las mujeres y muchachas de limitar su conducta sexual. Por ejemplo, los padres de adolescentes, e incluso de hijos más jóvenes usan la frase, "Cuiden a sus gallinas que mi gallo anda suelto”. Además, el investigador encontró que los avances respecto a la equidad entre los jóvenes durante el noviazgo tienden a disminuir después del matrimonio y el primer hijo.

\section{Involucrar a hombres jóvenes y} muchachos adolescentes en Brazil (Gary Barker) $^{13}$

De Keijzer continuó con la investigación de Gary Barker del Instituto Promundo (Brasil) con muchachos
"EQUIDAD DE GÉNERO" se refiere a hombres jóvenes que:

- Son generalmente respetuosos en sus relaciones con mujeres jóvenes y actualmente están buscando relaciones basadas en la igualdad e intimidad más que en la conquista sexual. Creen que los hombres y mujeres tienen derechos iguales y que las mujeres tienen tanto deseo sexual y "derecho" a la agencia sexual como los hombres.

- Buscan cómo ser padres activos, es decir, creen que deben tomar la responsabilidad económica y por lo menos asumir cierta responsabilidad en el cuidado de los hijos. Ellos han demostrado ser partícipes al involucrarse, al menos en cierta medida, en el cuidado de sus hijos al mostrarse preocupados por proveer de lo necesario a sus hijos, y/o tomando un papel activo en el cuidado de la salud de sus hijos.

- Asumen algunas responsabilidades en cuestiones de salud reproductiva, lo cual incluye tomar la iniciativa para discutir cuestiones de salud reproductiva con su pareja, ya sea utilizando condones o ayudando a su pareja a adquirir o utilizar un método anticonceptivo.

- No usan la violencia contra las mujeres en sus relaciones íntimas, y se oponen a la violencia contra las mujeres. Esto puede incluir a hombres jóvenes que reportan haber sido violentos hacia una pareja femenina en el pasado, pero quienes actualmente creen que la violencia contra las mujeres no es una conducta aceptable, y no justifican esta conducta en otros hombres.

adolescentes en los Estados Unidos y Brasil. Barker estudió un grupo de 25 hombres jóvenes entre los 15 y 21 años de

\footnotetext{
I2 Gabriela Rodriguez y Benno de Keijzer. 1997. "Sexualidad juvenil: relato etnográfico de una comunidad rural”, trabajo presentado en la conferencia Aproximaciones en la Diversidad Juvenil, El Colegio de México, 5-6 noviembre.

${ }^{13}$ Para una discusión más a fondo de estos conceptos, referirse a Gary Barker. 2000. "Gender equitable boys in a gender equitable world: Reflections from qualitative research and program development with young men in Rio de Janeiro, Brazil" ["Igualdad de género entre muchachos en un mundo con desigualdad de género: reflexiones de una investigación cualitativa y de un programa de desarrollo con hombres jóvenes en Rio de Janeiro, Brasil”], Sexual and Relations Therapy [Terapia Sexual y de Relaciones de Pareja] 15(3): 263-282. Barker puede también ser contactado directamente en la dirección g.barker@promundo.org.br
} 
¿QUÉ HACE QUE ALGUnOS MUChachos sean más equitativos respecto al género?

- Son generalmente respetuosos en sus relaciones con mujeres jóvenes y actualmente están buscando relaciones basadas en la igualdad e intimidad más que en la conquista sexual. Creen que los hombres y mujeres tienen derechos iguales y que las mujeres tienen tanto deseo sexual y "derecho" a la agencia sexual como los hombres.

- Buscan cómo ser padres activos, es decir, creen que deben tomar la responsabilidad económica y por lo menos asumir cierta responsabilidad en el cuidado de los hijos. Ellos han demostrado ser partícipes al involucrarse, al menos en cierta medida, en el cuidado de sus hijos al mostrarse preocupados por proveer de lo necesario a sus hijos, y/o tomando un papel activo en el cuidado de la salud de sus hijos.

- Asumen algunas responsabilidades en cuestiones de salud reproductiva, lo cual incluye tomar la iniciativa para discutir cuestiones de salud reproductiva con su pareja, ya sea utilizando condones o ayudando a su pareja a adquirir o utilizar un método anticonceptivo.

- No usan la violencia contra las mujeres en sus relaciones íntimas, y se oponen a la violencia contra las mujeres. Esto puede incluir a hombres jóvenes que reportan haber sido violentos hacia una pareja femenina en el pasado, pero quienes actualmente creen que la violencia contra las mujeres no es una conducta aceptable, y no justifican esta conducta en otros hombres.

edad que viven en un contexto de bajos recursos económicos en Río de Janeiro, donde la masculinidad está fuertemente asociada con una limitada participación en la salud reproductiva y el cuidado de los hijos, un sentido de derecho libre en cuanto al sexo con las mujeres, y una tolerancia bastante generalizada de la violencia contra mujeres. Barker procuró entender por qué aún en grupos como éste algunos muchachos actuaban de forma más igualitaria con las mujeres. El estudio identificó una minoría importante de hombres jóvenes que demostraron un grado mayor de equidad de género en conducta y actitudes en sus interacciones con mujeres jóvenes que el de sus compañeros y de los hombres adultos en el mismo grupo. Los resultados (ver tabla) dan a entender que algunos muchachos son capaces de reflexionar y crecer a partir de experiencias críticas, como por ejemplo cuando ven las consecuencias de que un hombre sea violento con una mujer o abandone a sus hijos. Además, es más probable que estos muchachos tengan hombres o padres en sus vidas que les sirven como modelo de respeto en sus relaciones con las mujeres, y que estén a favor de la participación masculina en la salud reproductiva.

Una de las lecciones más importantes aprendidas del trabajo de Promundo es que la juventud masculina es una población heterogénea, con una amplia gama de comportamientos y prioridades que 


\section{La masculinidad como un factor de riesgo}

PARA LAS MUJERES

Violencia

ITS/VIH/SIDA

Embarazos indeseados

Depresión

Oportunidades limitadas
PARA LOS HOMBRES

Encarcelamiento

Abuso del alcohol y drogas

Suicidio

Violencia/homicidio

Expectativa de vida reducida cambian con el tiempo. Cuando los muchachos interactúan con adultos $y$ padres que participan en el cuidado de los hijos o en labores domésticas, con mujeres involucradas en posiciones de liderazgo, o con hombres que demuestran responsabilidad respecto a la salud reproductiva, es más probable que ellos sean más flexibles en sus ideas acerca de los papeles que juegan hombres y mujeres, y que participen en la salud reproductiva. Entre las implicaciones del programa se encuentran: apoyar a los hombres jóvenes que tengan una actitud más igualitaria en cuestión de géneros; procurar los medios para que éstos sirvan cómo modelos para otros jóvenes; crear grupos alternativos de compañeros que tengan actitudes $y$ conductas igualitarias, y al mismo tiempo impulsar una concientización en la comunidad en contra de la violencia doméstica y a favor de la igualdad de género. También es importante educar a los muchachos desde temprana edad, a partir de alrededor de los diez años, cuando están más susceptibles a asimilar de forma favorable los puntos de vista alternativos sobre los papeles de género mas- culino. Los programas para jóvenes necesitan animar a los muchachos a reflexionar sobre sus propias experiencias y a cuestionar las normas tradicionales sobre género, lo que incluye analizar los beneficios para ellos mismos y para las mujeres de una mayor igualdad de géneros. Los muchachos también deben aprender nuevas habilidades de comunicación y negociación, ya que las investigaciones y la experiencia de campo sugieren que la clave para reducir la transmisión del VIH y lograr una mayor participación masculina en la salud reproductiva radica en mejorar la comunicación entre las parejas. Finalmente, dado que muchos jóvenes creen que el coito es el único tipo de "relación sexual que cuenta", los programas deben trabajar con los muchachos para explorar otras formas de expresar afecto, incluyendo la expresión sexual.

\section{Abordando las masculinidades en México (Benno de Keijzer) ${ }^{\text {I4 }}$}

Finalmente, de Keijzer habló de su propio trabajo con Salud y Género enfocando el tema de las "masculinidades". Salud y

\footnotetext{
${ }^{14}$ Para una discusión más a fondo sobre estas cuestiones, referirse a Benno de Keijzer. 1999. "Reaching men for health and development", ["Atraer la atención de los hombres para la salud y el desarrollo"] en Linda King (ed.), Questions of Intimacy: Retbinking Population Education. [Cuestiones de Intimidad: Reconsiderando la Educación en Poblacion]. Hamburg: UNESCO.
} 
Género es una organización civil radicada en México y dedicada a estudiar y transfomar algunas de las principales consecuencias de las relaciones de género en la salud reproductiva, sexual, y mental de mujeres y hombres.

A partir de 1990, de Keijzer y sus colegas han llevado a cabo talleres con una población de hombres y muchachos muy diversa. En estos talleres, los hombres exploran cómo las masculinidades tradicionales presionan a los hombres a presentar la imagen de fuertes, competitivos, e invulnerables, a evitar la intimidad (con mujeres y con otros hombres), y a profesar a la misoginia y la homofobia. Estos talleres también ayudan a los hombres a entender cómo la masculinidad hegemónica se convierte en un factor de riesgo tanto para mujeres como para hombres (ver tabla), y contribuye a que los hombres tengan expectativas de vida más cortas con un déficit promedio de hasta seis años o más en México en comparación con las mujeres.

Salud y Género actualmente está incrementando su capacidad para evaluar y documentar el impacto que efectúa en hombres y mujeres. Específicamente, está intentando determinar la manera de estudiar los cambios no únicamente de actitud, sino también en conducta en los hombres que asisten a sus talleres de masculinidad, y también cómo estos cambios afectan la familia, el trabajo, y las relaciones con la comunidad. En el futuro, Salud y Género dará prioridad a sus intervenciones sobre paternidad, la participación masculina en el proceso de parto, el cese de la violencia contra las mujeres, y la asistencia a los hombres jóvenes a abordar el problema del VIH/SIDA.

\section{Discusión}

En la discusión, varios participantes mencionaron la necesidad de hablar sobre como dotar de poder a los hombres, y de cómo echar abajo el mito de que todos los hombres son poderosos. En la socialización de los muchachos hacen falta las habilidades de negociación, comunicación, autoconfianza, y conciencia, habilidades que les serían útiles a los hombres adultos también. Según demuestran estas investigaciones, la falta del sentido de poder entre los hombres puede traducirse en comportamientos negativos que afectan gravemente a las mujeres. No habrá ningún cambio duradero para todos sin una búsqueda de cómo cambiar las masculinidades.. Con este fin en mente, los participantes discutieron la necesidad no de enseñarles a los hombres cierta conducta o papel, sino de darles espacio para la reflexión.

Los participantes también reenfatizaron la paternidad inminente (particularmente entre padres primerizos) como un momento útil para la intervención. De Keijzer dijo que una de las experiencias de mayor impacto para Salud y Género ha sido el hacer que los hombres reflexionen sobre sus propios padres, y utilizar dicha reflexión como punto de partida para empezar a planear lo que quieren ser ellos como hombres y como padres. 


\section{COMENTARIOS DE LA COMUNIDAD DE PATROCINADORES Y AGENCIAS DE IMPLEMENTACIÓN}

Todos los esfuerzos descritos anteriormente han sido fomentados por instituciones que han demostrado creatividad $\mathrm{e}$ innovación en su apoyo de programas que intentan enfrentar este difícil tema. Representantes de algunas de estas instituciones protagonistas compartieron las experiencias de sus organizaciones en el fomento de la experimentación y el cambio, así cómo sus visiones del trabajo y las prioridades en el futuro.

\section{Subcomité de Hombres y Salud} Reproductiva del Grupo de Trabajo Interagencial de Género (IGWG) de la USAID

\section{$A$ continuacion, una declaración de Sam Clark:}

En 1997 la Oficina de Población convocó a la IGWG, con una amplia participación de agencias colaboradoras, patrocinadores, $y$ otros individuos $y$ agencias que trabajan en el campo de la salud reproductiva. El Subcomité de Hombres y Salud Reproductiva, uno de cuatro comités que operan dentro de la IGWG, tiene reuniones trimestrales, a las que asisten entre 25 y 35 individuos en representación de unas 30 organizaciones. Los valores centrales del Subcomité son: promover el potenciamiento de las mujeres y la equidad de géneros, particularmente en la salud reproductiva; incrementar el apoyo de los hombres a aquellas prácticas que favorecen la salud sexual y reproductiva de las mujeres y el bienestar de los hijos; y promover mejoras en salud sexual y reproductiva para hombres y mujeres. Hemos escogido tres áreas prioritarias para nuestro trabajo: los adolescentes masculinos, la protección doble desde la perspectiva de género, y la violencia basada en género.

Hay una tensión sana dentro del Subcomité de Hombres y Salud Reproductiva entre aquéllos que quieren enfocarse en los programas de salud reproductiva que involucran a los hombres para servir a las necesidades de las mujeres, hijos/as u hombres; en contraposición a aquellos cuya preocupación principal es tratar la falta de equidad de género a través de programas de salud reproductiva. Déjenme darles un ejemplo. Se puede implementar un programa de promoción del condón para hombres que tenga éxito en incrementar el uso del condón, con resultados benéficos para la salud de hombres, mujeres, $y$ niños, pero que sea totalmente neutral en lo que se refiere a equidad de género. En contraste, se podrían promover los condones de una manera que enfatice la equidad de hombres y mujeres y así incrementar el uso del condón y la equidad de géneros al mismo tiempo. El Subcomité enfatiza este último enfoque, utilizando estrategias de equidad de género para mejorar los resultados en salud, y este debería ser nuestro principal "valor agregado."

Las actividades del Subcomité han buscado establecer un foro para el intercambio de ideas e información, impulsando 
las mejores prácticas favorables a los hombres y a la salud reproductiva, asesorando a la USAID y otras agencias interesadas, y monitoreando proyectos financiados por el Subcomité. Entre los retos que enfrenta el Subcomité se halla el de establecer un consenso dentro de un grupo muy diverso, y el de decidir y actuar con medidas concretas. Debo enfatizar que no somos un comité autónomo, sino que trabajamos en colaboración con los otros tres comités de trabajo de la IGWG.

Es importante abordar el trabajo con los hombres de manera empática. Muchas frases se utilizan para describir el papel de los hombres en la salud reproductiva, tales cómo "participación masculina", "participación de hombres", "los hombres y la salud reproductiva", "participación de los hombres en la salud reproductiva", y "los hombres cómo pareja”. Yo personalmente favorezco un enfoque de "los hombres como personas" en oposición al enfoque de "participación masculina”, que es más común. Debe comprenderse que los hombres benefician de su participación al igual que las mujeres, y que ellos no evitan su participación intencionalmente para lastimar a sus parejas, sino que los hombres tradicionalmente no han tenido lugar en el entorno de los servicios de salud reproductiva y debe encontrarse una forma de institucionalizar su participación.

El asunto de la relación entre la sexualidad y el poder debe ser presentado explícitamente, tanto dentro del Subcomité como en otras partes, y no sólo de manera implícita cómo se ha hecho en el pasado. Un ejemplo de un tema de sexualidad dirigido a los hombres son los tabúes culturales que vedan la masturbación, caso que se da en el subcontinente Indio. En dichas culturas, los hombres jóvenes pueden sentir que literalmente no tienen ninguna forma aceptable de expresión sexual que no sea el coito, incluso si esto significa arriesgarse a contraer VIH/SIDA con una sexoservidora. Hay que hacer legítimas formas alternativas de expresión sexual.

En cuanto a los siguientes pasos, nuestra agenda inconclusa es muy amplia y esperamos retomar parte de la agenda de acciones que surjan de esta reunión sobre el poder en las relaciones sexuales. Seguiremos avanzando con todos nuestros temas prioritarios. Además, nosotros vemos la necesidad de llevar a cabo una investigación adicional sobre la "desviación positiva” (aunque este término quizá sea poco apropiado dado que connota una "desviación negativa" problemática). Por último, el Subcomité ha apoyado la elaboración de recursos prácticos, entre ellos un CD-ROM titulado "Apoyando la Integración de los Hombres", y una sección especial en un portal en la Web dedicada a los hombres y la salud reproductiva (en www.rho.org- pulse en "Men and Reproductive Health"). Nosotros también apoyamos el desarrollo de protocolos accesibles para la salud reproductiva de los hombres, como la "Guía de Orientación: Los Hombres y la Salud Reproductiva", un curso de capacitación para el profesional de servicios de salud, y un documento de indicadores para satisfacer todas las necesidades de los programas orientados hacia el trabajo de campo. 


\section{El Fondo De Población De Las}

\section{Naciones Unidas (UNFPA)}

\section{Declaración ofrecida por Laura Laski:}

Debido a las Conferencias de Cairo y Cairo +5 , cuando hablamos de la población, ahora nos referimos a la salud sexual y reproductiva de las mujeres, sus derechos, educación, potenciamiento, igualdad y equidad. En el UNFPA hemos promovido programas de calidad en la salud reproductiva para servir las necesidades individuales y para asegurar el derecho a decidir. Sin embargo, la realidad es que la política y los programas de salud reproductiva frecuentemente ignoran la sexualidad y las relaciones de poder, aunque estos sean fundamentales para la mayoría de los problemas de salud sexual y reproductiva. Hoy en día la epidemia del VIH ha realzado la urgencia de enfrentar temas en poder y sexualidad en los programas del UNFPA.

Bajo nuestro nuevo liderazgo, el UNFPA está aconteciendo un proceso importante de realineamiento. Los elementos de este proceso incluyen:

- Incrementar nuestra capacidad para hacer que cada programa en cada país rinda cuenta de sus resultados

- Incorporar temas como la sexualidad y el poder dentro de nuestra agenda de salud reproductiva. Al personal técnico de la organización se le capacitará en sexualidad, empezando por los equipos de apoyo en los respectivos países e incluyendo al personal de las oficinas generales. Se crearán herramientas de programación para instar a las oficinas de cada país a apoyar la inclusión de la sexualidad en entornos donde se trate el tema de la salud reproductiva.
- Dar prioridad a los/las adolescentes. Pese a las acciones legales tomadas en muchos países con la finalidad de proteger los derechos reproductivos y asegurar una igualdad en el género a partir de la conferencia en el Cairo, a las adolescentes todavía les falta protección legal esencial. Por ejemplo, muchos países no imponen una edad mínima para el matrimonio, lo que hace muy difícil prevenir no únicamente un embarazo temprano sino también el contagio de VIH. Además, muchos paises no reconocen el concepto de la violación dentro del matrimonio.

- Mejorar la calidad de atención. Estamos trabajando en colaboración con la UNICEF, la OMS, la OIT, y otras ONG para desarrollar una definición compartida de la calidad de atención; esto estrecharía la relación entre los prestadores de servicios de salud reproductiva y los usuarios. También ayudaría a los prestadores de servicios cuando aborden el empalme entre el poder y el género en las relaciones y la sexualidad.

Necesitamos ser específicos acerca de los cambios de comportamiento que pedimos de los hombres, ya sea en su papel de creadores de políticas y líderes de la comunidad o como maridos y padres. El trabajo de la UNFPA apunta a incrementar el apoyo masculino hacia las

\section{La epidemia del VIH ba agregado un sentido de urgencia para abordar los temas del poder y la sexualidad en los programas de la UNFPA}


decisiones de las mujeres en cuanto a su salud reproductiva, e incrementar su participación en una paternidad y conducta sexual y reproductiva más responsable, que incluye (entre otros) la planificación familiar, el cuidado prenatal, el cuidado materno y la salud de los hijos, la prevención de ITS y la participación equitativa en el cuidado de los hijos.

\section{Population Council}

El poder en las relaciones sexuales ba sido un tema de discusión importante dentro de las oficinas regionales del Population Council en los últimos años. Ayorinde Ajayi, Director del Programa en la región Sureste de África, es una de las personas que ba retomado esta agenda y reporta avances. A continuación se encuentra su declaración:

En representación de las oficinas regionales del Population Council, hablaré acerca de la evolución del trabajo de mi programa, que trata el poder en las relaciones sexuales. Hemos llegado a este campo más o menos recientemente, realizando serios esfuerzos apenas hace un par de años después de una reunión a principios del año 2000 en torno a los/las adolescentes y cuestiones sobre las parejas.

Gran parte de mi interés en el tema se deriva del hecho de que vivo en un medio en que el poder en las relaciones sexuales tiene muchas manifestaciones negativas. El VIH por ejemplo, es una enfermedad que afecta a un número cada vez mayor de mujeres adolescentes, y este fenómeno se ubica en el centro de la dinámica del poder. Las muchachas adolescentes entre I5 y I9 años de edad en Kenia tienen una probabilidad siete veces mayor de contraer VIH que los muchachos de la misma edad, y el 60\% de las nuevas infecciones del VIH están dentro de este grupo etareo. También sabemos que en al menos $40 \%$ de los casos, la primera relación sexual de muchachas kenianas entre 15 y 19 años de edad es forzada. Por eso es muy difícil para nosotros cruzarnos de brazos y decir que distribuyan condones. Tenemos que preocuparnos por lo que sucede una vez que los condones se distribuyen.

Mis colegas y yo decidimos examinar la posibilidad de tomar algunas acciones dentro de nuestros programas existentes para profundizar nuestra comprensión de la variable del poder. Empezamos con un conjunto de hipótesis básicas:

- Los desequilibrios del poder basados de género dentro de las relaciones limi$\tan$ a las mujeres en sus intentos de negociar el sexo seguro y de ejercitar su derecho de elección reproductiva.

- Estos desequilibrios en el poder limitan a las mujeres a la hora de discutir asuntos de salud reproductiva con sus parejas.

- Los programas de salud reproductiva tienen la responsabilidad de ayudar a las mujeres a abordar y resolver este desequilibrio.

Con la ayuda de Julie Pulerwitz ${ }^{15}$, elaboramos doce preguntas a incluir en encuestas regionales. En una encuesta, el Proyecto Global de Intervención con Jóvenes de Frontiers (Frontiers Global Youth Intervention Project, un estudio financiado por la USAID que busca establecer una línea base en Kenia Occidental), se hicieron preguntas sobre 
la discusión de la anticoncepción, el número de hijos deseados, el uso de parte de la pareja de métodos de barrera física, $y$ las percepciones del poder relativo dentro de las relaciones. A partir de los resultados del estudio, determinamos que la habilidad de las mujeres para abordar temas de salud reproductiva y discutirlos es crítica y está vinculada con su poder dentro de las relaciones.

Nuestros siguientes pasos en la región incluyen:

- Elaborar y validar una versión de la Escala de Poder en las Relaciones Sexuales;

- Comparar las respuestas de los padres con las de adolescentes para ver cómo está cambiando la percepción del poder de las mujeres dentro de las relaciones a través de las generaciones;

- Incluir preguntas específicas sobre el uso consistente del condón y las relaciones actuales en la próxima fase de estudios de campo (ya que estro no figuró en la primera fase); y

- Elaborar y comprobar las intervenciones para incrementar el poder relativo de las mujeres dentro de las relaciones y después incluirlas en los estudios de intervención en la región.

\section{Programa Horizontes (Horizons) del} Population Council

\section{Declaración de Andrew Fisher:}

Hablaré de los estudios actuales y direcciones futuras relacionadas al poder en las relaciones sexuales en el Programa Horizons, tomando las conclusiones del trabajo de mis colegas Ellen Weiss y Julie
Yo vivo en un ambiente en donde el poder en las relaciones sexuales tiene muchas manifestaciones negativas... Por eso, se nos bace muy difícil sentarnos $y$ decir que distribuyan condones. Tenemos que preocuparnos sobre lo que sucederá con el condón una vez que este disponible.

Pulerwitz. Nuestra perspectiva sobre el poder y las relaciones sexuales tiene tres elementos:

1. El género, la sexualidad, las dinámicas del poder, y los cambio de conducta son temas transversales que afectan todos los aspectos del VIH/SIDA.

2. Estas interpretaciones son relevantes a nivel mundial pero varían en su intensidad y efectos y son difíciles de influir programaticamente.

3 . Antes de que estos constructos puedan ser medidos o tratados a través de programas, deben ser operacionalizadas.

Los hallazgos de estudios selectos en el África resaltan algunos de los retos que implica abordar el poder en las relaciones sexuales. En Zimbabwe, descubrimos que las mujeres creen que una mayor participación masculina mejoraría la comunicación y fortalecería los lazos familiares, pero que hablar sobre el sexo seguro puede conllevar conflictos, ya que implica la falta de confianza. Los hombres quieren ser más activos en el cuidado prenatal, pero temen perder respeto debido a que el embarazo es "cosa de mujeres". En Nigeria, una investigación sobre la protección doble reveló que los clientes y

${ }^{15}$ Para La Escala de Poder en la Relación Sexual de Pulerwitz y colegas, ver texto en la página 44. 


\section{Modelo ecológico: El poder se expresa en muchos niveles y puede ser}

influenciado en muchos niveles

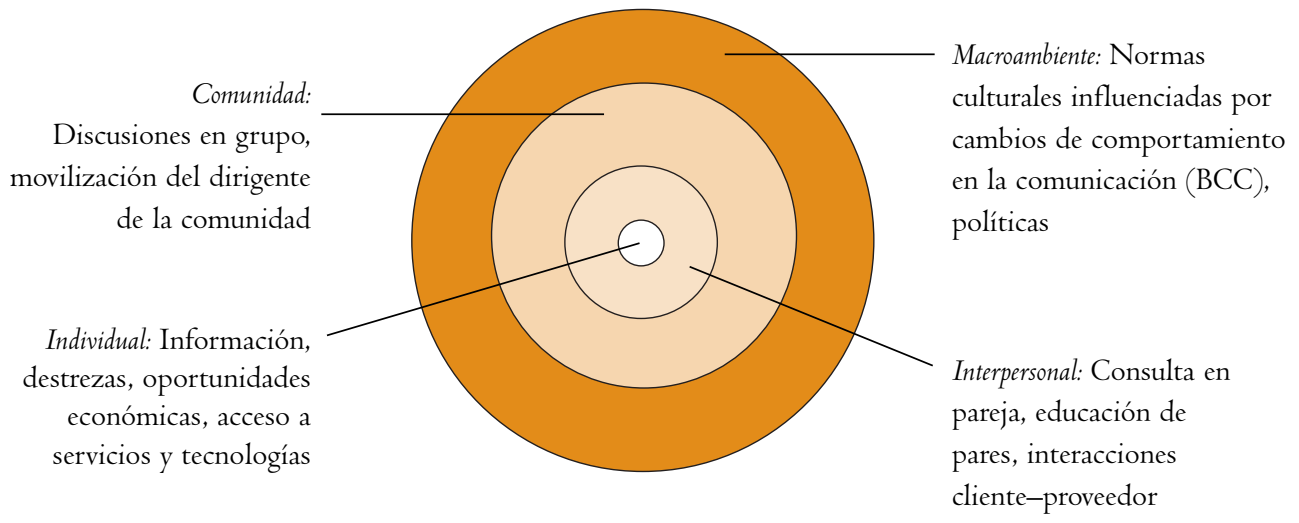

prestadores de servicios de salud citan a los hombres cómo el obstáculo principal para la protección contra el embarazo no deseado y las infecciones transmitidas sexualmente. Las mujeres reconocen que sus maridos tienen otras parejas, y están conscientes del riesgo de contraer VIH/ITS, pero temen al rechazo, al conflicto, y a la violencia si se enfrentan a sus parejas con la necesidad de una protección doble. En Tanzania, un estudio reciente sobre la disposición de revelar al compañero/a el seroestatus positivo indicó que la mayoría de las mujeres no querían hacerlo por miedo de la reacción de su pareja. Mientras que apenas el 5\% de las mujeres entrevistadas en realidad experimentaron una reacción negativa después de haber compartido la información (i.e., ser culpada, abusada, o abandonada), el $38 \%$ tenía historial de violencia con su pareja.

Estos hallazgos implican que la intersección del poder y el género claramente crea obstáculos para la comunicación en la pareja, la negociación de sexo más seguro, y la reducción de riesgo del VIH/SIDA. Múltiples actores, incluyendo parejas, profesionales de la salud, y el resto de la comunidad, deben ser abordados. A través de un modelo ecológico (ver tabla), se puede ver que el poder es expresado a múltiples niveles (el comunitario, el interpersonal, el individual, y el macroambiental), y que cada uno de estos niveles sugiere distintos tipos de intervenciones.

Cuando miramos hacia el futuro, vemos la necesidad de:

- Proseguir con la investigación a nivel de pareja y de intervenciones en la

Las dinámicas del poder relacionado con el género son claros obstáculos para la comunicación entre la pareja, la negociación de un sexo más seguro y la reducción del riesgo por $\mathrm{VIH} / \mathrm{SHDA}$ 
comunidad (las variables independientes);

- Buscar la forma de influir directamente en los elementos de poder en las relaciones sexuales (la variable dependiente);

- Dar cuenta de los múltiples niveles de intervención en diferentes contextos culturales (las variables de intervención);

- Dar el tiempo suficiente para que las intervenciones influyan en los complejos elementos de género y poder; y

- Depurar nuestros descubrimientos, diseminarlos y buscar cambios en los programas.

\section{Fundación MacArthur}

\section{Declaración de Carmen Barroso:}

Los conocimientos adquiridos sobre los lazos entre el poder y la sexualidad han influido en la distribución de fondos de la Fundación MacArthur desde que empezamos a aportar recursos para asuntos de población en 1986.

El Poder. Reconocer la importancia del poder en las relaciones de género es un proceso a largo plazo y nosotros hemos dado apenas los primeros pasos. Todavía existen retos enormes, tanto a nivel de políticas como a nivel de comportamientos $y$ actitudes individuales. Esto es el caso sobre todo en el área de la participación masculina. Cuando MacArthur comenzó a otorgar fondos en este campo en 1992, el discurso predominante era el de la "responsabilidad masculina". Los programas culpaban a los hombres por su descuidada conducta casi de la misma forma en que las mujeres habían sido culpadas por tener muchos hijos. El objetivo también era muy limitado: de
El mayor incentivo para adoptar comportamientos responsables es la esperanza en el futuro, y eso no lo podemos crear con proyectos localizados en un solo sector. Sólo las políticas multisectorales pueden revertir las tendencias macroeconómicas que generan un aumento en la pobreza.

convencer a los hombres que adoptaran la anticoncepción o apoyaran su uso por su pareja. Las relaciones de género dispares no se cuestionaban, más bien eran reforzadas. Las vasectomías, por ejemplo, se promovieron como una forma de permitir a los hombres de tener sexo sin responsabilidades. MacArthur instó a los individuos, y posteriormente a las organizaciones que se interesaron, a ayudar a los hombres para desarrollar relaciones igualitarias y para crear nuevas masculinidades. Sin embargo, parece haber más interés por parte de las mujeres la en participación de los hombres que por parte de los hombres mismos. La razón principal probablemente es que a pesar de que los hombres tienen mucho que ganar con relaciones más igualitarias, esto podría no resultarles obvio de inmediato. Otras razones, sin embargo, podrían también estar relacionadas a la forma en que se diseñan los programas. Por ejemplo, al evitar la sexualidad y enfocarse únicamente en la reproducción, los programas de salud soslayan muchas de las necesidades de los hombres.

El Sexo. La principal vía en la que MacArthur ha tratado de abordar el sexo ha sido a través de la educación sobre la sexualidad. Apoyamos a individuos y organizaciones que han elaborado metodologías innovadoras para involucrar a 
personas jóvenes en amplias discusiones acerca de toda la gama de temas relacionados a una sexualidad placentera y responsable. Nuestros donandos están actualmente en transición, de la elaboración de modelos a la gestión frente a gobiernos, con la finalidad de convencerlos de implementar educación sexual amplia y sensible a la sexualidad y al género.

No basta, sin embargo, con la educación sexual; las personas jóvenes deben tener incentivos para aplicar lo que aprenden. El mayor incentivo para adoptar comportamientos responsables es la esperanza en el futuro, y eso no lo podemos crear con proyectos localizados en un solo sector. Sólo las políticas multisectoriales pueden revertir las tendencias macroeconómicas que generan un aumento en la pobreza. MacArthur está consciente de que los fondos para programas de población son limitados, y por eso está creando un área complementaria de desarrollo en donde serán abordadas las cuestiones de la globalización.

MacArthur también ha intentado incluir otros tipos de disparidades de poder en su programación. Tomando en cuenta la disparidad en las relaciones de poder entre los países del Norte y del Sur, hemos creado oficinas en varios países y los hemos dotado de personal de esos mismos países. La mayoría de nuestras partidas la extendemos a organizaciones indígenas en naciones en vías de desarrollo y apoyándolas en la creación de redes internacionales. Y nosotros hemos intentado tratar cuestiones de desequilibrio de poder con nuestros donandos, al intentar ser lo más transparentes y dar la mejor rendición de cuentas posible. Finalmente, hemos mencionado las desigualdades de género junto con otras desigualdades, tales como aquellas basadas en la raza y la clase.

MacArthur acaba de pasar por un proceso de reevaluación de estrategias. En nuestros nuevos lineamientos el cambio más importante ha sido la introducción de un énfasis sobre la prevención de morbilidad y mortalidad maternas y la promoción de la salud sexual y reproductiva y los derechos de las personas jóvenes. Eso sí, hemos mantenido nuestra estructura de trabajo conceptual básica de los derechos humanos e igualdad de géneros en la que el poder en las relaciones y la sexualidad son tan relevantes como siempre.

\section{Fundación Ford}

\section{La declaración ofrecida por Sarab Costa:}

Desde principios de los noventa, los programas de la Fundación Ford han abordado el género, la elección sexual y reproductiva, y la educación sexual y la salud, incluyendo VIH/ SIDA, dentro del contexto de las relaciones de género y las necesidades más amplias de desarrollo de los individuos y las comunidades. Once de catorce de las oficinas de campo de Ford tienen programas de Salud Sexual y Reproductiva.

La Sexualidad. Nosotros nos dimos cuenta que la sexualidad subyace la salud reproductiva, sobre todo la salud frente a la creciente epidemia de VIH/SIDA. De ahí, en 1994 la mesa directiva de la Fundación aprobó la incorporación de la sexualidad cómo un componente crítico en su agenda de salud reproductiva. Este avance nos permitió promover un concepto más amplio del bienestar sexual no 
sólo como un determinante subyacente de mejores índices de salud, sino también como una meta deseable en sí misma. Ford apoya tanto la investigación como los programas de capacitación en sexualidad. Los programas exploran la definición, la realización y la representación de los patrones sexuales en diferentes culturas. Así se busca entender cómo los comportamientos sexuales contribuyen a los problemas sexuales y reproductivos. Nuestras actividades también están enfocadas en una educación sexual amplia, y en servicios "amigables" a la juventud. Actualmente estamos llevando a cabo una valoración de nuestro trabajo sobre la sexualidad en todo el mundo, con la intención de definir futuras estrategias para llevar nuestro trabajo a niveles superiores.

El Potenciamiento. Otra de las principales preocupaciones de Ford ha sido concentrarse en el potenciamiento de las mujeres. A mediados de los noventa concluimos que las mejoras en la salud reproductiva dependían de avances complementarios en el estatus de las mujeres dentro de la sociedad y dentro de sus comunidades y familias. Como resultado, la Fundación incrementó su atención en el trabajo orientado al género que incluía a los hombres y desafiaba la desigualdad entre los géneros.

La Reestructuración de la Fundación. La reestructuración de la Fundación en 1997 resultó en la incorporación de la salud sexual y reproductiva dentro del nuevo Programa de Desarrollo Comunitario y el fortalecimiento de activos, partiendo de la premisa de que la salud reproductiva afecta la capacidad de trabajo de las personas y conduce a una vida satisfactoria.
Hemos descubierto las oportunidades y los retos que se presentan al valorar la salud sexual y reproductiva como una posesión bumana y social vital dentro de una agenda de desarrollo más amplia dirigida a la reducción de la pobreza y la injusticia.

La salud reproductiva también moldea la habilidad de construir relaciones interpersonales e intergeneracionales sólidas, basadas en la igualdad de géneros. Al mismo tiempo, permite obtener el conocimiento y las destrezas necesarias para lograr cambios en el entorno social, comunitario, legal y político. El programa ha comenzado por enfocar más directamente las condiciones socioeconómicas generales que subyacen la falta de equidad y la dinámica de los géneros en las relaciones sexuales. Si por un lado el amplio enfoque de la Fundación demuestra la necesidad de programas y de coordinación intersectorial, por otro lado enfrenta el reto adicional de encontrar formas de iniciar y mantener estas relaciones. Actualmente estamos evaluando diferentes estrategias destinadas a vincular los comportamientos de salud reproductiva con la conducta de la economía en términos prácticos, en varios países (entre ellos la India, Kenia, y Nigeria) y también estamos trabajando en la creación de indicadores para valorar este trabajo de una manera más eficiente.

Durante los últimos diez años, nuestro enfoque se ha ampliado significativamente, $y$ hemos descubierto las oportunidades y los retos que se presentan al valorar la salud sexual y reproductiva cómo una vital posesión humana y social dentro de 
una agenda de desarrollo más amplia dirigida a la reducción de la pobreza y la injusticia. Durante los próximos diez años la meta global de la programación de salud sexual y reproductiva de la Fundación Ford será ayudar a individuos, familias y comunidades a establecer las condiciones necesarias como para lograr índices de salud positivos. Esas condiciones incluyen una sexualidad sana y placentera, equidad en las relaciones de género, la elección reproductiva, redes sociales y conocimientos y destrezas. Entre las estrategias para lograr este objetivo se cuentan:

- Sostener y mantener una definición amplia y un enfoque para la salud sexual y reproductiva dentro de las agendas de desarrollo;

- Promover dentro de los sectores de salud más frágiles los cuidados de salud sexual y reproductiva sensibles al género y enfocadas en el/la cliente; y

- Fortalecer la capacidad local de identificar vías para construir la gama de condiciones humanas y sociales necesarias para mantener la salud.
La Agencia Estadounidense para el

Desarrollo Internacional (USAID),

División VIH/SIDA

\section{La Declaración de Paul Delay:}

Me gustaría mostrarle al grupo algunos datos abrumadores sobre la dinámica de la transmisión del VIH en la región subSahara en África que resaltan la vulnerabilidad de las muchachas en base a su género. Estos datos ilustran el problema que enfrentamos: esencialmente una epidemia desencadenada en mujeres jóvenes que ha sido provocada por la conducta masculina. Los varones demoran cerca de diez años más que las mujeres en infectarse y morir (ver cuadro). Esto significa que las mujeres ya tienen años de vivir con el SIDA antes de buscar servicios de salud reproductiva y métodos de planificación familiar. Este hecho presenta un gran reto en cuanto a la forma de estructurar programas. Por ejemplo, para cuando una mujer llegue a una clínica de planificación familiar en Kenia, puede ser ya muy tarde para evitar que se infecte. Cerca del $80 \%$ de aquellas mujeres que serán infectadas a lo largo de sus vidas, ya han sido

PREVALENCiA DEL VIH (\%) EN MUjeres embaraZAdas I 996 Y población General 1995-I996, Centro urbano de Zambia

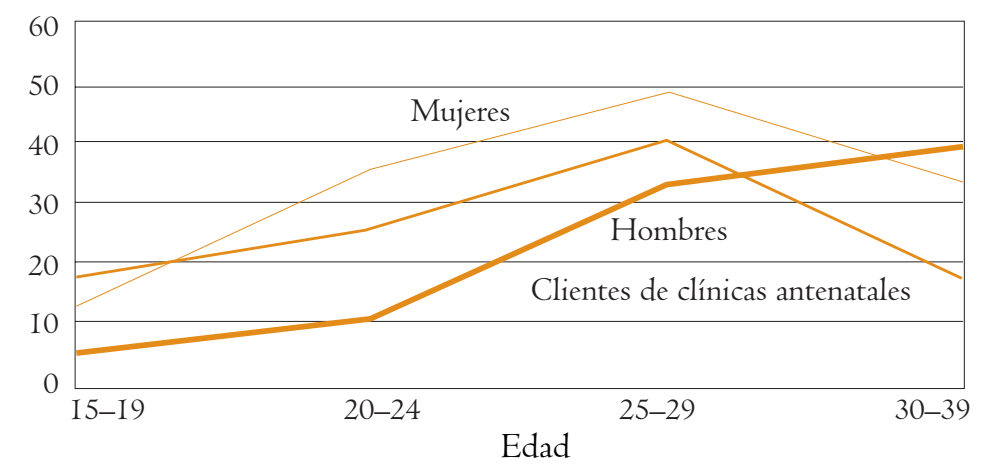

Fuente: K. Fylkesnes et al. 1998. "Studying dynamics of the HIV epidemic: Population-based data compared with sentinel surveillance in Zambia", ["Estudiando la dinámica de la epidemia del VIH: Datos basados en la población comparados con una vigilancia centinela en Zambia”], AIDS I2 (I0): I227-I234. 
infectadas para ese momento. Por lo tanto, es absolutamente imprescindible encontrar la forma de lograr que las jóvenes comprendan el poder y el género. Ahora delinearé la evolución de las disposiciones sobre género que ha establecido la USAID y lo que mis colegas y yo enfrentamos al desarrollar nuestro trabajo sobre el género y el poder dentro de una agencia como la USAID.

Después de las conferencias del Cairo y Beijing, en 1996, la USAID aprobó el Plan de Acción de Género para impulsar a las mujeres en la agenda de desarrollo. Más recientemente, esta agencia ha decidido que las limitaciones de género sean contempladas en su programación al aprobar nuevos lineamientos para la inclusión de cuestiones de género en el diseño de programas y procedimientos de la agencia. Como Sam Clark explicó anteriormente, el Grupo de Trabajo Interagencial sobre el Género (IGWG) se estableció en 1997.

Sin embargo, a pesar de este arduo trabajo, aún quedan preguntas difíciles. Delinearé cuatro retos interrelacionados que enfrentamos al intentar trabajar con el género y el poder:

I. Interpretar los resultados que se derivan de modelos de cambio de conducta con enfoques biomédicos y tradicionales. Hace diez años nuestros estudios eran sobre todo biomédicos y enfocaban los cambios de modelos de conducta y el tratamiento de las ITS. Más tarde, a mediados de los noventa, cuando hubo numerosos brotes de infecciones y nada parecía funcionar, hubo un giro hacia los determinantes socioeconómicos de vulnerabilidad tales como inequidad de género y pobreza. Sin embargo,
La dinámica de la transmisión del VIH en la región subsábara en el África ilustra el problema que enfrentamos: esencialmente una epidemia desencadenada en mujeres jóvenes ocasionada por la conducta masculina. Los varones demoran cerca de diez años más que las mujeres en términos de infección y muerte.

cuando se empezaron a saber de casos de éxito-como en Tailandia y Uganda en 1996, 1997, y 1998-se dio un alejamiento de las determinantes socioeconómicas de vulnerabilidad, ya que las intervenciones en el cambio de conducta con el enfoque biomédico habían funcionado en algunos entornos. Hoy en día nos encontramos en una especie de limbo: estamos en un punto entre el enfoque a las causas subyacentes de la vulnerabilidad y las intervenciones técnicas más directas.

2. Ofrecer pruebas del "valor agregado" de programas sensibles al género. Es necesario que expliquemos claramente cómo un entendimiento de la relación entre género y poder puede ayudarnos en nuestras intervenciones, y que tipo de intervenciones se pueden hacer en realidad. Hay dos ejemplos de áreas de trabajo sobre VIH/SIDA donde el género y el poder son factores decisivos para el éxito de las intervenciones, estos son: (a) la asesoría y las pruebas voluntarias y (b) las intervenciones en los casos de contagio de madre a hijo. Ha habido grandes fracasos con dichas intervenciones en muchas partes del mundo porque las mujeres toman el camino de no examinarse, de no obtener los resultados de las pruebas, ni de 
llevarlos con sus familias y para luego recibir las terapias

3. Medir un cambio en las relaciones de poder. Como agencia, la USAID está bajo presión para reportar sus resultados $y$ así mantener el financiamiento de su programa a un nivel favorable. El reto está en identificar los instrumentos apropiados para registrar el cambio logrado, no sólo en las relaciones de poder, sino también en la transmisión del VIH o en el uso de la planificación familiar. Tales cambios son paulatinos y difíciles de captar.

4. Los prejuicios contra los programas sensibles al género y "el potenciamiento de las mujeres". La agenda y el potenciamiento de las mujeres puede ser percibido como un proyecto feminista o izquierdista. De ahí, debemos encontrar una forma de hacer que estos conceptossean más aceptables o tolerados y menos extremistas.

Todas mis propuestas para avanzar requieren la ayuda de los aquí presentes:

- Demostrar que el potenciamiento del género es el eslabón que faltaba para incrementar el uso de la planificación familiar y reducir la transmisión del $\mathrm{VIH}$;

- Elaborar lineamientos claros y herramientas para facilitar nuestros proyectos y programas de campo para tratar las inequidades de género; y

- Desarrollar mayor sofisticación política en cuanto a nuestro lenguaje y los argumentos que usamos para "vender" nuestros proyectos. Debemos presentar nuestros planteamientos de tal forma que tengan resonancia con quienes tienen poder de decisión en nuestro financiamiento.

\section{Discusión}

Un participante argumentó que mientras tengamos un modelo de pareja sexual, se puede suponer que han practicado sexo seguro y que ha sido por consentimiento mutuo. De hecho una gran proporción de relaciones son forzadas y distan mucho de ser seguras, y debemos atender este hecho en nuestros programas.

Otro comentó que dentro de las relaciones de poder desigual, las mujeres usan formas de poder encubiertas y mecanismos de adaptación para sobrellevar estas situaciones. Las mujeres calladas quizá dejan que sus hombres se desahoguen, mientras que las que hablan mucho pueden estar soportando la carga de la violencia. A partir de su experiencia en el trabajo con mujeres golpeadas, otra participante recalcó que muchas mujeres no están listas para dejar a sus maridos abusadores porque en realidad tienen fuertes lazos emocionales con los hombres que las golpean. Explicó que podríamos arriesgar las relaciones de estas mujeres, en casos en que ellas no quieren que su relación termine.

Finalmente, otra participante, haciendo eco de un diálogo anterior, lamentó la dificultad de tomar la sexualidad en cuenta en estas discusiones sobre relaciones sexuales. "La consecuencia", dijo, "es trabajar con un modelo reproductivo con un agregado de sexualidad, con un campo de acción limitado a parejas heterosexuales y que da la espalda a los conocimientos revolucionarios del trabajo sobre sexualidad generados en los últimos 20 años”. El moderador comentó: "Parece que la sexualidad es un globo que se va volando". 


\section{UNA MIRADA HACIA EL FUTURO: LOS GRUPOS DE TRABAJO}

Para la última sesión, los participantes se dividieron en tres grupos de trabajo para la última sesión: Metodologías para la investigación y la evaluación, Intervenciones para la entrega de servicios, e Intervenciones en la comunidad y en los medios. Estos grupos se formaron para que las personas se incorporaran a ellas de acuerdo a sus intereses, así permitiendo la discusión de algunos temas en mayor detalle. También fue el momento en la reunión para concretar futuras direcciones en nuestro trabajo. Se le pidió a cada grupo que trajera dos o tres recomendaciones para una acción inmediata y dos o tres metas a largo plazo.

\section{Grupo de trabajo \#I: Metodologías} para la investigación y la evaluación Julie Pulerwitz de PATH y Ellen Weiss del Centro Internacional para la Investigación sobre las Mujeres (ICRW) moderaron una discusión de cuestiones metodológicas en el grupo más grande. El grupo comenzó por discutir la utilidad del constructo del poder a través de las culturas, dada la variedad de expresiones que encuentran el poder y la sexualidad en ellas. Algunos participantes consideraban necesario implementar localmente todas las medidas a nivel local. Otros señalaron lo útil que resultaría combinar medidas universales con otras específicas, de modo que las primeras facilitaran estudios multilocales comparativos y las segundas permitieran medidas adaptadas a cada lugar. Los participantes subrayaron la importancia de la investigación cualitativa para la elaboración de medidas válidas, en términos de validez del constructo (e.g., que se mida lo que se quiere medir) y validez del contenido (e.g., que se toquen todos los subdominios relevantes). Las medidas válidas son esenciales para demostrar que los cambios en la dinámica del poder produzcan un impacto positivo sobre la salud. Muchos miembros del grupo también recomendaron que el control que las mujeres logren ejercer sobre su sexualidad sea un resultado importante que se pueda medir. Para demostrar la capacidad predictiva del poder en su influencia en las consecuencias sobre la salud reproductiva y la sexualidad, es necesario realizar estudios longitudinales. Además se necesitan análisis a planos múltiples para documentar cambios en la dinámica del poder a nivel individual, de la pareja y de la comunidad. Surgió también una última acotación: que la investigación-acción que mida los cambios en las dinámicas de poder debe prever la necesidad de un compromiso amplio de parte de la comunidad.

Entre los asuntos en que se podrían tomar acciones inmediatas están las siguientes:

- Identificar ejemplos de medidas, particularmente índices y escalas que se han usado para medir el poder a nivel individual y de relaciones.

- Iniciar estudios para validar las mediciones del poder dentro de diferentes contextos.

- Involucrar a las ONG que trabajan 
con género cuando se realiza una investigación para examinar el poder y la sexualidad

Entre las metas a largo plazo se contaron:

- Realizar estudios longitudinales sobre una intervención, contando aquellos que se enfocan en cuestiones estructurales, para luego examinar cambios en la dinámica del poder a nivel individual, de pareja y de la comunidad que ocurren a lo largo del tiempo.

- Elaborar y comprobar los indicadores de cambios institucionales y comunitarios que pueden ocurrir como resultado de los cambios en el poder individual y relacional.

- Promover el financiamiento a largo plazo mediante patrocinadores con la finalidad de realizar investigaciones-

\section{La escala de poder en la relación sexual}

Un AVANCE METODOLÓgico RECIENTE, citado numerosas veces durante la reunión, fue el desarrollo de una Escala de Poder en la Relación Sexual (EPRS) por Pulerwitz y colegas. La EPRS se creó para valorar el poder en las relaciones íntimas. La escala, que consiste de 23 reactivos que se califican en 4 puntos en la escala de Likert, puede dividirse en dos subescalas. Las subescalas producen estimados de dos dimensiones conceptuales de las relaciones de poder: (1) Dominio en la Toma de Decisiones; y (2) Control de la Relación. Las subescalas se pueden usar por separado o en combinación, conforme con los requisitos de la investigación. La subescala de Dominación en la Toma de Decisiones contiene preguntas sobre quién tiene la última palabra en varias decisiones (e.g.) "Mi pareja generalmente decide si vamos a tener sexo". La subescala de Control de la Relación contiene preguntas acerca de la naturaleza de la relación, por ejemplo, "La mayor parte del tiempo, hacemos lo que mi pareja quiere hacer".

Dos versiones equivalentes al EPRS fueron elaboradas, una en español y otra en inglés. Los reactivos se diseñaron partiendo de una perspectiva teórica que menciona explícitamente el sexo y el poder en combinación con el aporte de grupos de discusión en que participaron mujeres latinas y africano-americanas en los Estados Unidos. Los reactivos incorporan eventos comunes tanto a las relaciones entre parejas casadas como entre parejas de novios, y además trata el poder sexual y el poder en otras áreas de la relación íntima.

Ha sido comprobado la coherencia interna de la EPRS. Como parte de la evaluación psicométrica original de la EPRS, datos adicionales fueron recopilados de sujetos de estudio sobre el abuso físico y el sexo forzado en su relación actual, el uso del condón, la satisfacción en la relación y una variedad de variables socio-demográficas. Como se había avizorado, una relación con un historial de violencia física y sexo forzado tenía una correlación negativa con la EPRS. El uso consistente del condón, un nivel educativo más alto y la satisfacción en la relación se correlacionaban de forma positiva con la EPRS.

La Escala de Poder en la Relación Sexual se ha usado o adaptado para otras poblaciones en Kenya, Zimbabwe, Estados Unidos y México.

Para una discusión más a fondo, refiérase a Julie Pulerwitz, Steven L. Gortmaker, y William Dejong. 2000. "Measuring sexual relationship power in HIV/STD research", ["Midiendo el poder en la relación sexual en la investigación de VIH/ETS"], Sex Roles $42(7): 637-660$. 
acciones que procuren cambiar las dinámicas del poder.

\section{Grupo de trabajo \# 2: Intervenciones} en la entrega de servicios

Elaine Murphy de PATH y Martha Brady del Population Council facilitaron la discusión de intervenciones en la entrega de servicios. El grupo reconoció la necesidad de un enfoque multisectorial para tratar cuestiones de inequidad de género de una manera más amplia, mencionando la posibilidad de aportes significativos en el sector salud. Por ejemplo, existen numerosas oportunidades de mejora en todos los niveles de servicio dentro de una gama de sistemas de cuidado de la salud. El grupo discutió la necesidad de experimentar con nuevos modelos de entrega de servicios que vayan más allá del entorno clínico tradicional. Sugirieron concentrar mayores esfuerzos en las comunidades.

Acciones inmediatas que se podrían plantear incluyen:

- Redefinir de la "calidad" para incluir una discusión de los desequilibrios en el poder entre parejas sexuales y su influencia sobre la toma de decisiones que afectan la salud reproductiva.

- Cambiar las normas de cuidado para que reflejen esta disparidad de poder al mejorar/expandir el contenido de la capacitación de profesionales de la salud; refinar los protocolos de servicio donde sea necesario; y elaborar nuevas y mejores herramientas e indicadores para la evaluación de los servicios

- Elaborar un inventario de potenciales "puertas de entrada" que sirvan para lograr que los hombres se comprometan en el apoyo eficaz a la pareja y la inclusión de servicios que sean particularmente accesibles para la pareja como tal.

- Explorar formas de acercarse a varios segmentos de la población joven, sin descuidar las diferenciales de poder $y$ género entre hombres y mujeres

- Experimentar en torno a la relación entre la salud reproductiva y la generación de ingresos en poblaciones de mujeres adolescentes y adultas.

- Diseñar y someter a prueba intervenciones dirigidas a comprometer a padres primerizos.

Las metas a largo plazo incluyen:

- El diseño de servicios de salud reproductiva que atiendan las necesidades de mujeres expuestas al tráfico sexual

- Concientización de niños entre los 6 a I0 años mediante actividades, reconociendo que la socialización de los niños pequeños influye su entendimiento y percepción de las normas y los papeles del género.

- Sensibilización de los trabajadores de salud para que atiendan las necesidades específicas de personas homo y bisexuales en entornos escogidos.

El grupo citó la iniciativa de USAID, "La Maximización del Acceso y la Calidad” (MAQ), y al Subcomité sobre Hombres y Salud Reproductiva del Grupo de Trabajo Interagencial sobre Género como dos mecanismos interagenciales existentes que podrían ser utilizados para asegurar el logro de un reconocimiento mínimo de las cuestiones de poder en los intercambios entre profesionales de la salud y sus clientes, así mejorando la calidad de los mismos. 
Grupo de trabajo \#3: Intervenciones en la comunidad y en los medios

Este grupo, facilitado por Ronnie Lovich de Save the Children y Nancy Yinger de la Population Reference Bureau, dedicó mucho tiempo a la discusión de los lazos entre la comunidad y los medios. Miembros del grupo identificaron tres actividades inmediatamente que se pueden iniciar inmediatamente:

- Efectuar valoraciones retrospectivas para apreciar la evolución de los programas.

- Ayudar a patrocinar redes constituidas por periodistas, investigadores, personas con poder de decisión política y miembros de la comunidad

- Realizar entrenamientos compartidos sobre la forma de discutir temas en sexualidad, ya que hasta los participantes que acuden a reuniones de este tipo experimentan dificultades para discutirlos.

Las metas a largo plazo incluyen:

- Concretar acuerdos sobre la definición y los parámetros de la sexualidad y expandir el diálogo actual.

- Vincular la equidad social con la equidad de género, y reconocer que si los hombres ven el poder como un juego en que se pierde o se gana, nosotros debemos encontrar formas de exponer claramente los benficios que les ofrecen las negociaciones equitativas. Una forma de comprometerlos puede ser examinando cómo la pobreza, el desempleo y la falta de educación despoja a los hombres de su poder, para luego vincular estos problemas con las inequidades de género.
- Establecer el uso del autodiagnóstico, del aprendizaje participativo y de la toma de acciones como prácticas habituales en el trabajo de grupo a nivel comunitario. A este mismo nivel se reconoció la necesidad de incrementar las técnicas para entrar a la comunidad, escuchar a las personas, entender su percepción de sus propias necesidades, y reconocer los conocimientos que ya poseen, así facilitando el diálogo, y por último, movilizando acciones de la comunidad para producir cambios.

\section{Discusión}

Varios participantes comentaron que el proceso de escuchar a los miembros de la comunidad puede servir para despejar muchas de las suposiciones sobre las normas comunitarias que existen en la mente de quienes provienen del medio urbano y son egresados de instituciones de educación superior.

El reunir a miembros de la comunidad para hablar sobre las normas también les proporciona oportunidades para darse cuenta de cuanto realmente saben de lo que piensan otros miembros de su comunidad. Bárbara Ibrahim del Population Council, quien encabezó la sesión, informó sobre reuniones comunitarias en Egipto que brindaron una oportunidad para que las comunidades revaloraran las prácticas y los valores subyacentes a la mutilación genital femenina, y de este modo determinar si estas aún servían a los intereses de la comunidad. Los cooperantes supusieron que la comunidad resistiría la discusión de estos temas, pero no fue el caso. 
La pregunta de cómo los hombres pueden beneficiarse del cambio fue abordada por varios participantes. Un participante dijo que existen varios estudios que interrogan a los hombres en cuanto a sus sentimientos sobre las normas de género prevalecientes. Para sorpresa de muchos, los entrevistados dijeron que las hallaban muy limitantes, como una camisa de fuerza. Así, pues, una forma de ver "que ganan los hombres" es de pensar que los hombres tendrán la oportunidad de quitarse la camisa de fuerza. Otro participante sugirió que el beneficio para los hombres al cambiar las normas de género sea más fácilmente percibido por ellos en tratar el papel de padre, ya que ellos desean la seguridad de sus familias, la supervivencia de sus hijos y la prevención de daños a sus hijas. Otro participante destacó algo que estamos olvidando, y es que los hombres están en la misma comunidad que las mujeres: ellos podrían obtener ganancias personales al incrementar la intimidad sexual y al gozar de relaciones más igualitarias.
Por último, otro participante tocó el tema de la situación en sociedades patriarcales donde otros familiares sienten estar en desventaja o amenazados en su poder por el fuerte vinculo sexual entre la pareja. Para que un hombre rompa con las normas existentes, debe estar dispuesto a sostenerse ante las presiones familiares $y$ comunitarias. Este abordaje enfatiza la importancia de trabajar a muchos niveles diferentes y de comprometer tanto a personas de autoridad dentro de la comunidad cómo a las parejas. 
Judith Bruce del Population Council cerró la reunión con un resumen de los temas que surgieron durante el transcurso de los dos días y algunas cuestiones que habría que tomar en cuenta para el futuro.

Bruce comenzó diciendo que en virtualmente todas las presentaciones y observaciones se reconoció que tanto hombres como mujeres tienen mucho que ganar del cambio, a nivel individual, en dinámicas en la pareja y a nivel de la familia. A nivel de la comunidad, los beneficios derivados de ajustes en las disparidades del poder son vistos actualmente con un mayor consenso en el sentido de que contribuyen positivamente, elemento sin duda indispensable a nuestra capacidad para contener la epidemia del $\mathrm{VIH} / \mathrm{SIDA}$; fomentar la regulacion de la fertilidad elegida, eficaz y segura; reducir la mortalidad materna; y mejorar la salud infantil.

Nuestra capacidad para medir el cambio todavía sigue limitada. Nuestra habilidad para relacionar los cambios en los patrones de comunicación entre pareja con las supuestas reducciones en las disparidades del poder también se ve limitada a la hora de evaluar los resultados. Sin embargo, por ahora no podemos darnos el lujo de elaborar en secuencia las medidas idóneas antes de actuar. Aun ante la ausencia de las pruebas que podríamos necesitar, tenemos el deber de intervenir. Documentos avalados a nivel internacional han validado una amplia gama de derechos humanos, reproductivos y sexuales, entre ellos el derecho a conocer
En virtualmente todas las presentaciones y observaciones se reconoció que tanto bombres como mujeres tienen mucho que ganar del cambio, a nivel individual, en dinámicas en la pareja y a nivel de la familia

nuestros cuerpos, controlar nuestra vida sexual y el derecho de tener conocimientos para proteger nuestra salud, aunque no siempre los medios para negociar a beneficio de ella. Bruce afirmó que, a corto plazo, el énfasis sobre la dimensión de los derechos en este trabajo podría ayudar a mantener nuestro impulso hasta que nosotros refinemos las destrezas de medición antropológica y de ciencias sociales que sostienen nuestro trabajo.

A lo largo de la reunión, se expresaron inquietudes sobre cómo ampliar el diálogo sobre el género y el poder para abarcar un espectro más diverso de comportamientos y necesidades sexuales. Bruce reconoció que esta reunión se diseño para abordar principalmente las relaciones heterosexuales y que estamos lejos de cruzar esa frontera. La sexualidad es un tema nuevo, y debemos presionar para definirla más allá de nuestras percepciones tradicionales de las relaciones masculinas/ femeninas.

Por último, Bruce describió su propia visión de los pasos deseables a seguir: 
- Incluir información acerca del impacto posible de la dinámica sexual de parejas en la información básica que es intercambiada entre cliente y profesionista en el campo de salud. En un servicio de planificación familiar por ejemplo, es insuficiente informar a las personas sobre los aspectos técnicos de un método y sus efectos secundarios. En un intercambio de información en esta época marcada por los riesgos de VIH y SIDA, y a la luz de todo lo que sabemos sobre la coerción y la violencia en las parejas sexuales, debemos reconocer a cada cliente como parte de una pareja sexualmente activa. Las personas necesitan entender que su conducta sexual y la de su pareja (o parejas) frecuentemente tienen un impacto significativo sobre su propia salud, y que estas conductas afectan la aceptabilidad, seguridad y probable eficacia de las tecnologías que se les ofrecen.

- Hacer pública la existencia de este tipo de poder, fomentando un diálogo a nivel comunitario que haga visible en el dominio público lo que ha sido considerado privado durante demasiado tiempo. Es importante reconocer que muchos contactos sexuales no son ni completamente voluntarios, ni seguros o placenteros. La palabra "sexo" no es obscena como la es la palabra "poder".

- Insertar en los sistemas convencionales de servicios de salud un entendimiento del poder en las relaciones íntimas, enfatizando los servicios de maternidad y de salud infantil. Paradójicamente, algunas de las implicaciones más sensibles de una disparidad de poder en las relaciones sexuales pueden ser aceptadas más fácilmente, en entornos tradicionales donde, por ejemplo, la transmisión madre-hijo/a del SIDA puede abrir una discusión con los hombres sobre como proteger a sus esposas/madres de sus hijos. Mientras trasladar la discusión sobre el poder en las relaciones sexuales al ámbito público dentro de la comunidad es absolutamente vital, también es importante, en palabras de Bruce, "retomar algunas de estas viejas y polvorientas infraestructuras $y$ tratar de ponerlas a tono".

- Al explorar el significado del poder en las relaciones sexuales para adolescentes, debemos elaborar nuestros mensajes tomando en cuenta edad, género, estado civil e intenciones en cuanto a la fertilidad. La posibilidad de tener una relación sexual voluntaria e informada de una adolescente soltera saliendo con un joven de su edad, difiere de manera importante de la de una adolescente casada con un hombre mucho mayor que se vea presionada para salir embarazada.

- Reconocer el fuerte vínculo que existe, particularmente para las mujeres, entre las mejoras en la salud y el cambio social y económico. Los programas deben encontrar mecanismos de apoyo funcionales y flexibles que integren ambos aspectos. Por ejemplo, debería otorgarse a los proyectos una fase diagnóstica que se implemente auténticamente en la comunidad, reservando algunas de sus decisiones y sus fondos para intervenciones potencialmente no relacionadas a la salud reproductiva (como clases de alfabetización, asociaciones de ahorro y otras estrategias de empoderamiento estrechamente 
relacionadas y frecuentemente vitales). ticularmente cuando se trabaja con La flexibilidad del financiamiento personas jóvenes. También será crítico debe coincidir con el compromiso a en nuestra búsqueda de medidas aprolargo plazo porque muchos de los cam- piadas definir cambios intermedios, bios que buscamos son imposibles de tales como un mayor diálogo entre las lograr u observarse a corto plazo, par- parejas, que son valiosos en sí mismos. 


\section{APÉNDICE: LOS PARTICIPANTES}

Robert Ainslie

Johns Hopkins University Center for

Communication Programs

rainslie@jhuccp.org

Ayorinde Ajayi

Population Council, Kenya

aajayi@popcouncil.or.ke

Hemant Apte

KEM Hospital and Research Centre

ham@pn2.vsnl.net.in

Humberto Arango

Federación Internacional de Planificación de la Familia/RHO (IPPF/RHO)

harango@ippfwhr.org

Michal Avni

USAID

mavni@usaid.gov

Carmen Barroso

MacArthur Foundation

cbarroso@macfound.org

Julie Becker

EngenderHealth

jbecker@engenderhealth.org

Robert Becker

Planned Parenthood of New York City

robert.becker@ppnyc.org

Stan Becker

Johns Hopkins School of Public Health

sbecker@jhsph.edu

Sandra Bjegovic

Population Council

sbjegovic@popcouncil.org

Ann Blanc

Blancroft Research International

ablanc@home.com

Susan Bloodworth

PATH, D.C.

sbloodworth@path-dc.org
Lisa Bohmer

Pacific Institute for Women's Health

1bohmer@piwh.org

Summer Boslaugh

Moriah Fund

sboslaugh@moriahfund.org

Martha Brady

Population Council

mbrady@popcouncil.org

Sarah Braunstein

Population Council

sbraunstein@popcouncil.org

Judith Bruce

Population Council

jbruce@popcouncil.org

Michele Burger

Consultora

mburger11@aol.com

Lucella Campbell

IPPF/RHO

lcampbell@ippfwhr.org

John Casterline

Population Council

jcasterline@popcouncil.org

Chris Castle

Population Council, D.C.

ccastle@pcdc.org

Jennifer Catino

Population Council, México

jcatino@popcouncil.org.mx

Margarita Cereijido

Washington Psychoanalytic Institute mrcereijid@aol.com

Amy Charney

Centre for Development and

Population Activities

acharney@cedpa.org 
Erica Chong

Population Council

echong@popcouncil.org

Sam Clark

PATH, D.C.

sclark@path-dc.org

Sarah Costa

Fundación Ford

s.costa@fordfound.org

Jane Cottingham

Organización Mundial de la Salud

cottinghamj@who.ch

Caroline Crosbie

Pathfinder International

ccrosbie@pathfind.org

Benno de Keijzer

Salud y Género

salygen@infosel.net.mx

Paul Delay

USAID

pdelay@usaid.gov

Judith Diers

Population Council

jdiers@popcouncil.org

Paul Dover

Universdad de Uppsala

Paul.Dover@antro.uu.se

Anne Dykstra

USAID

adykstra@usaid.gov

Nabila El-Bassel

Columbia University School of Social Work

ne5@columbia.edu

Julia Ernst

Center for Reproductive Law and Policy

julia.ernst@crlp.org

Marguerite Farrell

USAID

mfarrell@usaid.gov
Andrew Fisher

Population Council, D.C.

afisher@pcdc.org

Lynn Freedman

Center for Population and Family Health

lpf1@columbia.edu

Victoria Frye

Center for Health and Gender Equity

vfrye@genderhealth.org

Susana Galdos

Movimiento Manuela Ramos

sgaldos@manuela.org.pe

Susan Gibbs

Summit Foundation

sgibbs@summitfdn.org

Belkis Giorgis

Academy for Educational Development

bgiorgis@aed.org

Françoise Girard

International Women's Health Coalition

francoise@iwhc.org

Rachel Goldberg

Population Council

rgoldberg@popcouncil.org

Michelle Gray

Population Council, D.C.

mgray@pcdc.org

Margaret Greene

Population Action International

mgreene@popact.org

Alan Greig

Consultant

alangreig@earthlink.net

Jay Gribble

Georgetown University

jng@georgetown.edu

Alessandra Guedes

$\mathrm{IPPF} / \mathrm{RHO}$

aguedes@ippfwhr.org 
Geeta Rao Gupta

International Center for Research on Women geeta@icrw.org

Sarah Harbison

USAID

sharbison@usaid.gov

Tanya Harrel

SYNERGY Project

tanya@tvtassociates.com

Sarah Hawkes

Population Council, India

sarah@pcindia.org

Judith F. Helzner

$\mathrm{IPPF} / \mathrm{RHO}$

jhelzner@ippfwhr.org

Jennifer Hirsch

Rollins School of Public Health

jshirsc@sph.emory.edu

Susie Hoffman

HIV Center for Clinical and Behavioral Studies

hoffman@pi.cpmc.columbia.edu

Dale Huntington

Population Council, India

dhuntington@pcindia.org

Barbara Ibrahim

Population Council, Egipto

bibrahim@pccairo.org

Jodi Jacobson

Center for Health and Gender Equity

jjacobson@genderhealth.org

Anrudh Jain

Population Council

ajain@popcouncil.org

Carol Jenkins

National Institutes of Health

cjenkins@niaid.nih.gov

Inoussa Kaboré

Tulane University

ikabore@tulane.edu
Debra Kalmuss

Center for Population and Family Health

dk6@columbia.edu

Mihira Karra

USAID

mkarra@usaid.gov

Tabitha Keener

USAID

tkeener@usaid.gov

Sunita Kishor

MEASURE DHS+, Macro International

kishor@macroint.com

Peggy Koniz-Booher

University Research Co., LLC

pkoniz_booher@urc-chs.com

Kathleen Kurz

International Center for Research on Women

kkurz@icrw.org

Ana Langer

Population Council, México

alanger@popcouncil.org.mx

Laura Laski

UNFPA

laski@unfpa.org

Ann Leonard

Population Council

aleonard1@nyc.rr.com

Laurie Liskin

Johns Hopkins University Center for

Communication Programs

1liskin@jhuccp.org

Ronnie Lovich

Save the Children

rlovich@savechildren.org

Rebecka Lundgren

Georgetown University

lundgrer@gunet.georgetown.edu

Marjorie Macieira

Summit Foundation

mmacieira@summitfdn.org 
Kerry MacQuarrie

International Center for Research on Women

kerry@icrw.org

Purnima Mane

Population Council

pmane@popcouncil.org

Amanda Martin

Summit Foundation

amartin@summitfdn.org

Rabia Mathai

Cruz Roja Americana

mathair@usa.redcross.org

Donna McCarraher

Family Health International

dmccarraher@fhi.org

Ann McCauley

Horizons Program/International Center for Research on Women

amccauley@pcdc.org

\section{Michael McGee}

Planned Parenthood Federation of America mike.mcgee@ppfa.org

Therese McGinn

Center for Population and Family Health

tjm22@columbia.edu

Oma McLaughlin

Centre for Development and Population Activities omclaughlin@cedpa.org

Carey Meyers

Population Council

cmeyers@popcouncil.org

\section{Alice Miller}

Center for Population and Family Health am808@columbia.edu

\section{Suellen Miller}

Population Council

smiller@popcouncil.org

Luis Mora

UNFPA

luis.mora@eat.org.mx
Esther Muia

Population Council, Kenya

emuia@popcouncil.or.ke

Elaine Murphy

PATH, D.C.

emurphy@path-dc.org

Margaret Neuse

USAID

mneuse@usaid.gov

Susan Newcomer

National Institute of Child Health and Human

Development

newcomes@exchange.nih.gov

Constance Newman

PRIME Project

cnewman@intrah.org

Glenn Northern

Planned Parenthood Federation of America

glenn.northern@ppfa.org

Maureen Norton

USAID

mnorton@usaid.gov

Sia Nowrojee

Center for Health and Gender Equity

snowrojee@genderhealth.org

Tonya Nyagiro

Fundación de las Naciones Unidas

tnyagiro@unfoundation.org

Laura Nyblade

International Center for Research on Women lnyblade@icrw.org

Waafas Ofosu-Amaah

Banco Mundial

wofosuamaah@worldbank.org

Naana Otto-Oyotey

IPPF/Global Advocacy Division

nottooyotey@ippf.org

Emma Ottolenghi

Population Council, D.C.

eottolenghi@pcdc.org 
Saroj Pachauri

Population Council, India

monica@pcindia.org

Susan Palmore

Advance Africa

spalmore@advanceafrica.org

Rohini Pande

International Center for Research on Women

rpande@icrw.org

Richard Parker

Columbia School of Public Health

rgp11@columbia.edu

Angela Pattatucci-Aragon

National Institutes of Health

pattatua@csr.nih.gov

Wayne Pawlowski

Planned Parenthood Federation of America wayne.pawlowski@ppfa.org

Suzanne Petroni

US Department of State

s.petroni@state.gov

Patricia Poppe

Johns Hopkins University Center for

Communication Programs

ppoppe@jhuccp.org

Julie Pulerwitz

Horizons Program/PATH

jpulerwitz@pcdc.org

Estelle Quain

USAID

equain@usaid.gov

Jewel Quallo-Rosberg

Belize Family Life Association

bfla@btl.net

Rebeca Quiroga

PATH, D.C.

rquiroga@path-dc.org

Saumya RamaRao

Population Council

sramarao@popcouncil.org
May Rihani

Academy for Educational Development

mrihani@aed.org

Karin Ringheim

PATH, D.C.

kringheim@path-dc.org

Kim Rivers

Universidad de Londres

rkkstcp@ioe.ac.uk

Naomi Rutenberg

Population Council, D.C.

nrutenberg@pcdc.org

Diana Santillan

Empowerment of Women Research Program dsantill@jsi.com

Shira Saperstein

Moriah Fund

ssaperst@moriahfund.org

Zeba Sathar

Population Council, Pakistan

zsathar@pcpak.org

Sid Schuler

JSI Research and Training Institute

sid_schuler@jsi.com

Audrey Seger

USAID

aseger@usaid.gov

Myrna Seidman

Universidad de Georgetown

seidmanm@gunet.georgetown.edu

Susheela Singh

Alan Guttmacher Institute

ssingh@agi-usa.org

Jeff Spieler

USAID

jspieler@usaid.gov

Lovisa Stannow

Pacific Institute for Women's Health

1stannow@piwh.org 
Kellie Stewart

USAID

kestewart@usaid.gov

Lindsay Stewart

Pathfinder International

1stewart@pathfind.org

John Townsend

Population Council, D.C.

jtownsend@pcdc.org

Marcia Townsend

CATALYST

mtownsend@rhcatalyst.org

Soraya Tremayne

Universidad de Oxford

soraya.tremayne@anthro.ox.ac.uk

Stephanie Urdang

UNIFEM

stephanie.urdang@undp.org

Janneke van de Wijgert

Population Council

jvandewijgert@popcouncil.org
Carole Vance

Columbia University

csvl@columbia.edu

Mary Nell Wegner

EngenderHealth

mnwegner@engenderhealth.org

Ellen Weiss

Horizons Program/International Center for

Research on Women

eweiss@pcdc.org

Amy Weissman

Save the Children

aweissman@savechildren.org

Goran Wimmerstrom

Consultor

wimmerstrom@swipnet.se

Nancy Yinger

Population Reference Bureau

nyinger@prb.org 